\title{
HILGARDIA
}

A Journal of Agricultural Science Published by the California Agricultural Experiment Station

INSECT TRANSMISSION, HOST RANGE, AND FIELD SPREAD OF POTATO CALICO

D. R. PORTER

\section{INITIAL LOCALIZATION AND SUBSEQUENT SPREAD OF CURLY-TOP SYMPTOMS IN THE SUGAR BEET} KATHERINE ESAU 
INITIAL LOCALIZATION AND SUBSEQUENT SPREAD OF CURLY-TOP SYMPTOMS

IN THE SUGAR BEET

KATHERINE ESAU 



\title{
INITIAL LOCALIZATION AND SUBSEQUENT SPREAD OF CURLY-TOP SYMPTOMS IN THE SUGAR BEET ${ }^{1}$
}

\author{
KATHERINE ESAU ${ }^{2}$
}

\section{INTRODUCTION}

Studies made by Bennett (1934) on tobacco plants affected by curly top of the sugar beet indicate that the virus causing this disease moves within the phloem tissue, spreading through this channel from the site of inoculation to other parts of the plant. If this is true, the path of the virus depends on the vascular connection between the inoculated leaf and the other organs.

According to anatomical studies on curly-top-diseased beets, the first internal and external pathologic changes are definitely localized in the plant and their position is determined by the site of inoculation. The first part of the present paper discusses this localization of symptoms.

The second part deals with the course of phloem degeneration in the root. These studies give additional information on the spread of internal symptoms and strengthen the conclusions drawn in previous papers (Esau, 1933, 1934a, and 1935), especially as regards tissue relations of the curly-top virus. The observations upon protoplast degeneration in diseased root tips contribute toward the knowledge of the role of sieve tubes on the spread of the injurious agent in curly-top infection.

A description of the structure of healthy organs and tissues furnishes a basis for interpreting the phenomena observed in diseased plants.

\section{MATERIAL AND METHODS}

The methods employed in preparing material for microscopic study, as well as the origin and treatment of such material prior to fixation, were essentially the same as described in an earlier publication (Esau, 1933). The plants were grown in a greenhouse and were inoculated with curly top by means of the beet leafhopper, Eutettix tenellus (Baker).

Most of the material was killed in a chromo-acetic-formalin mixture (Esau, 1933); but some root tips were treated with a mitochondrial bichromate fixative made up as follows : 1 per cent solution of potassium bichromate, 1 per cent solution of chromic acid, and commercial formalin mixed just before using in a proportion of $5: 5: 1$. After 12 hours

1 Received for publication January 31, 1935.

2 Junior Botanist in Experiment Station. 
the material was placed in freshly prepared solution of the same composition, then, after an additional 12 hours, in 1 per cent solution of potassium bichromate. In this solution the material was left for 5 days, was then washed in water, dehydrated, and imbedded by the use of the butyl alcohol method (Esau, 1933).

The primary root structure of healthy and diseased plants was studied in root tips obtained from lateral roots of plants one to three months old. The diseased plants had been inoculated after they developed two to four foliage leaves. When root tips were sampled, the plants showed severe external symptoms of curly top.

In the study of the fleshy taproot, the time of inoculation was varied, and the plants were harvested so that roots in different stages of infection were available.

\section{LEAF AND HYPOCOTYL CONNECTION IN HEALTHY YOUNG PLANTS}

The vascular system of young beet plants will be briefly described with the aid of figures. Diagrams $B$ to $K$ of figure 1 represent transverse sections made at successive levels through a very young plant whose vascular system contained only primary tissues. Figure $1 A$ is the diagram of a slightly older plant seen from above. For convenience, the cotyledons have been numbered 1 and 2 , although there was no indication that either developed before the other. The foliage leaves have been numbered 1 to 5 in the order of their development.

In diagrams $B$ to $K$ of figure 1, small circles indicate the xylem, whereas the stippling designates the location of the phloem, which contained mature sieve tubes. As these diagrams show, the traces of the youngest leaves contain only phloem, indicating that the phloem develops sooner than xylem. The line separating the xylem and phloem in a bundle represents the cambium. The cotyledons or their traces are shown in all diagrams except $C$ and $D$.

The leaves of a beet are arranged in a spiral, so that relatively close behind the growing point the traces ${ }^{3}$ of the younger leaves are located nearer to the center than those of the older leaves (fig. $1 C$ ). At lower levels the traces become arranged in a ring, which first includes only the traces of the foliage leaves (fig. $1 D$ ) but farther down the cotyledonary traces also (fig. $1 G$ ). The arrows in figure $1 D$ and $E$ indicate that the traces of the fourth and of the third leaves split in two branches at a lower level, just above the insertion of the cotyledons. (See also fig. $2 I$ and $J$ ). These branches anastomose with the cotyledonary traces

\footnotetext{
3 The term trace is applied in this paper to the entire complex of bundles belonging
} to a given leaf. 
(fig. $1 E$ and $F$ ) above the region where all the bundles fuse to a ring. One branch of the trace of leaf 3 fuses with the trace of leaf 5 (fig. $1 E$ ), so that after the trace of the first cotyledon fuses with the ring of bundles, it is flanked by the traces of the third and fifth leaves (figs. $1 G$ and $2 J)$.
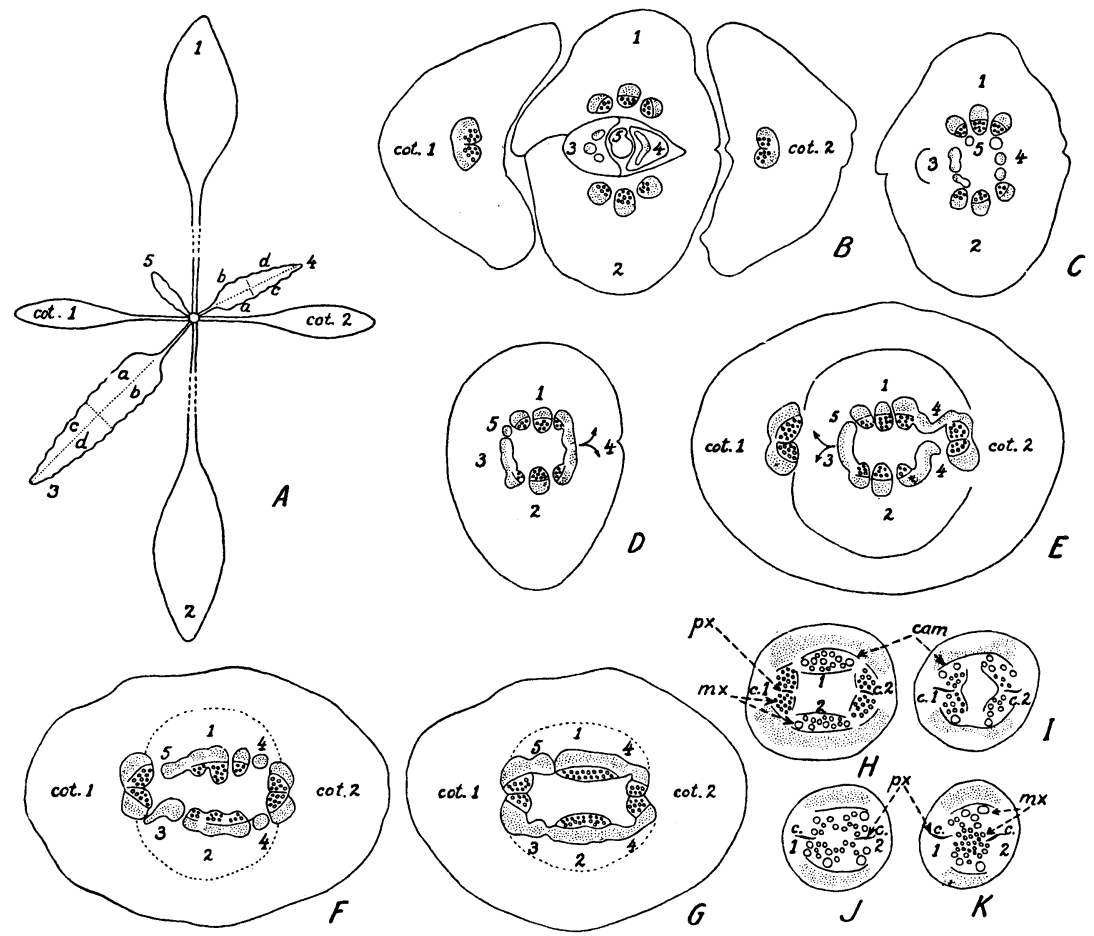

Fig. 1. $-A$, Diagram of a young plant $(\times 0.6) . B-K$, successive transverse sections through a young beet plant showing the vascular system: $B-D$, sections made above the insertion of cotyledons; $E-G$, cotyledonary plate; $H-K$, sections made below the insertion of cotyledons. The cotyledons were omitted in $C$ and $D$. $(B-G, \times 26$; $H-K, \times 51$.) cam, cambium; $c$ and cot, cotyledon; $m x$, metaxylem; $p x$, protoxylem. See text for explanation of numbers and lower-case letters.

Diagrams $H$ to $K$ of figure 1 show the orientation of the vascular tissues below the insertion of the cotyledons. In figure $1 H$ only the traces of the cotyledons and of the first two leaves are present. The pith occupies the center of the stele, and the xylem of all the traces is endarch.

The differentiation of the primary vascular tissue of the first two leaves is initiated in the leaves and then it progresses downward toward the hypocotyl. In the lower hypocotyl the vascular supply of the first leaves connects laterally with the cotyledonary traces, but later is directly joined to the primary vascular tissue of the root. At the level in figure $1 I$ this direct connection with the root was not yet formed. The 
xylem cylinder shows two gaps, which in an older plant would be occupied by the xylem leading to the first two leaves. The phloem of these two traces, however, is present in figure $1 I$.

In figure $1 J$ the xylem approaches the exarch condition, but some parenchyma cells still appear in the center. Figure $1 K$ shows how the tissues are arranged in the stele of the root. The xylem is exarch, and the pith is absent. The protoxylem was crushed at this stage of development. The centripetal metaxylem occupies the center of the stele, and the centrifugal metaxylem (Seeliger, 1919) occurs as rather large elements on both sides of the centripetal xylem. Although some of these centrifugal elements belong to the vascular system of the first two leaves, they cannot be definitely separated from the cotyledonary supply. The primary cambium will add secondary xylem elements next to the centrifugal metaxylem (fig. $2 N$ ).

When secondary growth occurs in beets, its vascular system becomes very complex, especially within the shortened stem above the cotyledons. As is well known (Artschwager, 1926; Seeliger, 1919), in the secondary development of the beet root several concentric rings of vascular tissue are formed (plate 2). The cotyledons connect only with the primary vascular tissue; the first two foliage leaves with the primary and the secondary tissue of the first ring. The subsequent leaves are not directly connected with the primary tissues, but each forms anastomoses with more than one of the secondary rings.

According to De Vries (1879), the general rule is that the larger vascular strands connect with the older, deeper rings in the root, the smaller strands with the outer, younger ones. He emphasized that the vascular supply of the leaves forms numerous anastomoses in the epicotyl and also that the rings of vascular tissue are connected with each other, so that materials translocated from a given leaf downward may be carried to any ring in the root.

Figure 2 shows how the vascular bundles of the different leaves are related to each other and to the rings of vascular tissue in the root in a young beet plant. Where the traces of the leaves occurred very close together, the bundles belonging to each trace have been marked off from those of the other traces by means of dotted lines. The cotyledons have been omitted in $A$ to $H$ of figure 2.

Below the insertion of a leaf, its trace fuses with the ring of bundles formed by the leaves located at higher levels. Before this fusion, certain bundles of the ring become rearranged so that a gap is formed in the ring, but, at lower levels, is closed by the trace of the nearest older leaf. The double arrows in figure $2 B, C$, and $I$ indicate where a gap will occur at a level below that shown in these diagrams. 


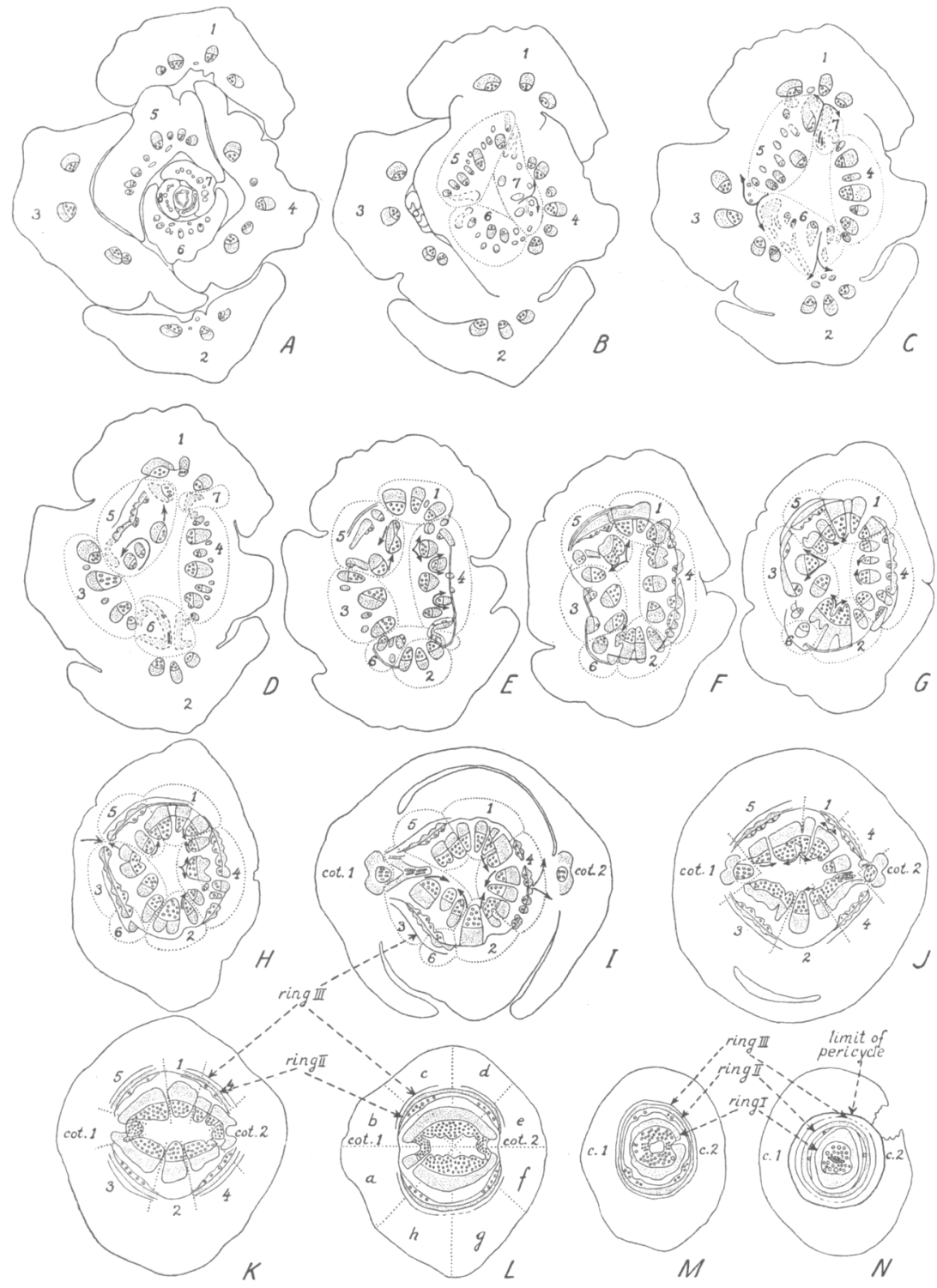

Fig. 2.-Successive transverse sections through a beet plant somewhat older than that of figure 1, showing the structure of the vascular system after the development of the first anomalous growth ring in the root: $A-H$, sections made above the insertion of cotyledons; $I-K$, cotyledonary plate; $L-N$, sections made below the insertion of cotyledons. The cotyledons were omitted in $A-H$. (All $\times 20$.) See text for explanation of numbers. 
At higher levels the small and large bundles of a trace occur at the same distance from the center, but at lower levels the smaller bundles are farther away. In the plant represented in figure 2 this condition may be observed in leaves 3,4 , and 5 . The large bundles of these leaves connect with the first ring in the root; the small bundles with the second ring.

Anastomoses, fusions, and renewed branching occur among the bundles arranged in the ring. Bundles of one leaf fuse with each other and with the bundles of other leaves. Arrows in figure $2 D$ to $J$ indicate where a fusion or a branching will occur at a lower level.

The region where the cotyledonary traces are about to fuse with the ring of bundles appears in figure $2 I$. As shown by a comparison of figures $1 F$ and $2 I$, in the younger plant the vascular supply of leaves 1 and 2 is more prominent than the supply of leaves 3,4 , and 5 , whereas in the older plant the opposite is true. In addition, the younger leaves in the older plant have established a connection with the second ring of vascular tissue in the root.

In figure $2 K$ the cotyledonary traces form part of the ring of bundles, and their primary cambium is continuous with that of the other bundles of this ring. In figure $2 L$ the cambium of the second ring forms a closed circle, and in figure $2 M$ the cambium of the third ring is continuous. Here the pith is still present; but it is absent in figure $2 \mathrm{~N}$, where the traces of the cotyledons have fused to form the diarch and exarch primary xylem plate of the root. This plate is surrounded by the secondary xylem of the first ring. The second ring of vascular tissue contains mostly phloem and but little xylem. The third ring at this level shows only cambium.

\section{LOCALIZATION OF SYMPTOMS DURING THE EARLY STAGES OF CURLY-TOP INFECTION}

External Symptoms.-The external symptoms of curly top develop on younger leaves than the one through which the virus was introduced into the plant. Sometimes they appear upon the leaf next to the inoculated one; sometimes on a leaf farther removed. When their development is retarded, they appear on a leaf distant from the site of inoculation.

As a general rule, in plants with fully expanded cotyledons and with first two leaves that have attained the length of about $2 \mathrm{~cm}$, the third leaf shows the translucent veins, which is the first symptom, when one of the two cotyledons or one of the first two leaves is inoculated. If the plant is younger and the two first leaves are about $1 / 2 \mathrm{~cm}$ in length, one of the frrst two leaves develops the earliest symptoms upon inoculation of one of the cotyledons. If the plants have eight to ten leaves, the symp- 
toms usually appear on the second or third leaf from the one inoculated, even when the latter is located next to the youngest at the time of inoculation. Deviations from this rule may occur, apparently in relation to the physiological condition of the plant. But in no case observed have translucent veins developed on leaves older than the one inoculated.

As Severin (1924) has shown, the curly-top virus occurs in the old leaves as well as in the young, so that the absence of external symptoms on the former does not signify that the virus failed to enter them. Rather, it indicates that only young differentiating leaves can develop such symptoms.

The differential effect upon young and old leaves has also been described in the case of tobacco mosaic. Though this virus may come to a high concentration in leaves that show no mottling (Holmes, 1928), it causes symptoms to develop only in plant parts that were differentiating when it entered them or after (Goldstein, 1926; Holmes, 1928). The early symptoms of tobacco mosaic may appear on the inoculated leaf itself if the latter is very young when the virus is introduced into it (Grainger and Heafford, 1933).

One-sided and unsymmetrical patterns of symptoms, similar to those observed by Holmes (1932) in mosaic tobacco, frequently occur in young sugar beets inoculated with curly top. When plants having two to four foliage leaves were inoculated through one of the two first leaves, the symptoms appeared about three days later on that side of the third leaf which was nearest to the inoculated leaf. Thus if the virus was introduced into the first leaf of a plant like that in figure $1 A$, the earliest symptoms developed in the quarter $a$ of the third leaf. If the second leaf was inoculated, the translucent veins were first observed in the quarter $b$ of the third leaf.

Next day the symptoms had frequently spread throughout the lamina of the third leaf, although remaining most marked in the quarter that showed the earliest symptoms. If the plants were slightly older and the third leaf was larger, the symptoms remained limited to one corner of the latter. This corner was frequently rolled inward, the rest of the lamina remaining flat.

In the cases described above, the fourth leaf developed the symptoms later than the third. Sometimes it showed a localization of symptoms like that in the third, at other times the clearing of veins developed simultaneously throughout the entire blade.

When the cotyledons were inoculated instead of the first foliage leaves, the initial symptoms developed in one or both of the two first foliage leaves in plants that were inoculated at the cotyledonary stage; in the third or fourth leaves in plants that had two foliage leaves when 
inoculated. When cotyledon 1 (fig. $1 A$ ) was inoculated, the first symptoms appeared in quarter $a$ of the third leaf, while an inoculation of cotyledon 2 caused such symptoms to appear throughout the fourth leaf. When the first symptoms developed on leaves 1 and 2, they remained restricted to one of the lower quarters or to the lower half of these leaves, or spread throughout the lamina.

As stated previously, the failure of old leaves to develop symptoms does not signify the absence of the virus from them. But if the initial symptoms occur on one side of the plant only, or if the young leaves show unsymmetrical patterns, the distribution of the symptoms seems to indicate the path of the virus in the early stages of infection.

Diagrams $B$ to $K$ of figure 1 indicate that the virus entering the first leaf and moving down the petiole could at the level shown in figure $1 D$ enter the fourth leaf. It could be translocated into the third leaf by being carried down to the hypocotyl or root, where all the traces merge to one ring of vascular tissue, or through the connection formed among leaves 1,5 , and 3 at about the levels shown in figure $1 E$ and $F$. As was mentioned before, the trace of leaf 3 branches above the insertion of cotyledon 1 and during this rearrangement anastomoses with the trace of leaf 5 , which in turn connects with leaf 1 (fig. $1 F$ ).

Virus entering leaf 2 could pass into the phloem of the third and fourth leaves at the level shown in figure $1 D$ or $G$. If introduced into the cotyledons, it could, at the level in figure $1 H$, enter leaves 1 and 2 . It could move into the third leaf from the first cotyledon at the level in figure $1 F$ or $1 G$, and into the fourth leaf from the second cotyledon at the level in figure $1 E$ or $G$.

The appearance of symptoms on one side of the leaf evidently depends upon the connection of this leaf with the one inoculated. The virus enters first that half of the leaf which is closest to the source of the inoculum. But the localization of the first symptoms in the lower quarters of the leaf does not necessarily indicate that the virus is absent from the upper. As in the tobacco leaf (Avery, 1933) the base of the blade in the sugar beet is the youngest portion of the leaf. In young leaves cleared in lactic acid one may see readily that the network of veins completes its development first in the upper and then in the lower portion of the blade. As mentioned before, younger tissues develop the symptoms more readily than older.

Internal Symptoms.-Like the external symptoms, the first signs of phloem degeneration are definitely localized in the plant, their site being related to the position of the inoculated leaf. The symptoms within the phloem were fully described in a previous paper (Esau, 
1935)..$^{4}$ In these experiments, primary hypertrophy and primary hyperplasia were particularly searched for.

Phloem degeneration may be recognized in the plant before the external symptoms become apparent. The clearing and the subsequent thickening of veins develop only after the initial disturbance in the phloem has occurred (Esau, 1933, 1935). In very young plants internal symptoms may show up about three days before the first clearing of veins becomes perceptible.

In one set of plants used in this study, transplanted seedlings were inoculated as soon as the two cotyledons had expanded, five infective beet leafhoppers being placed one afternoon upon one of the cotyledons. Next morning the insects were removed, and at the same time five plants were harvested. The sampling of plants was repeated daily for nine successive days. The plants were imbedded in paraffin in the usual manner and examined in stained sections.

In the plants harvested 12 hours after inoculation, abnormalities apparently were absent; but of the five plants fixed on the second day after the inoculation, two showed unmistakable signs of the disease. One of these contained occasional hypertrophied nuclei and inclusion bodies in certain phloem and pericycle cells in the traces of the first two leaves. In the other plant, the degeneration had progressed to the stage of primary hyperplasia, which was obvious in the phloem of the first two leaves immediately above the level where the cotyledons were attached (fig. $1 D$ ). Above this region only hypertrophy and inclusion bodies were perceptible, and the hypocotyl appeared to be free of abnormalities.

On the third day after the inoculation the results were similar to those obtained on the second, but on the fourth day all five plants showed abnormalities. Of these, two exhibited only early hyperplasia in the first two leaves. Two other plants showed more advanced hyperplasia than the first two, phloem degeneration being apparent not only in the foliage leaves but also in the inoculated cotyledon. In the foliage leaves of the fifth plant the hyperplastic tissue in the phloem was mature. The inoculated cotyledon showed hyperplasia in the newly developed phloem, the first sieve tubes formed having been obliterated in a normal manner (Esau, 1934b). In the three plants that showed pronounced phloem degeneration, the abnormalities were most obvious and reached the most advanced stage just above the insertion of the cotyledons (fig. $1 D$ ). In the first two leaves of the fifth plant the lateral bundles

4 Primary hypertrophy and necrosis signify abnormal growth and death of cells that lie adjacent to the first-formed sieve tubes. Primary hyperplasia denotes abnormal cell division near the same sieve tubes. Death and collapse of the hyperplastic tissue are designated as secondary necrosis, and growth and proliferation of parenchyma near the collapsed cells as secondary hypertrophy and hyperplasia. 
occurring near the inoculated cotyledon showed much more severe phloem degeneration than the other bundles of the same leaf. The trace of the third leaf in this plant contained only phloem but showed unmistakable abnormalities.

In some plants the first external symptoms were observed on the fifth day after the leafhoppers were placed on the seedlings. The internal symptoms were distributed like those in plants harvested on the fourth day, but the hyperplastic tissue was more extensive. The cotyledon that was not inoculated was free of phloem degeneration.

The localization of symptoms was still obvious in plants harvested nine days after the inoculation. Phloem degeneration was marked not only just above the insertion of the cotyledons, but also at higher levels and in the hypocotyl and in the root. The pathologic changes, however, were most severe at a level corresponding to that shown in figure $1 D$. Here primary hyperplasia was perceptible in the traces of all foliage leaves, while in the first two leaves the lateral traces adjacent to the inoculated cotyledon showed already the secondary changes-that is, secondary necrosis and secondary hypertrophy and hyperplasia. The cotyledon that was not inoculated was apparently free of abnormalities above the connection with the other leaves; but in the root the entire phloem was affected.

Plate 1 shows phloem degeneration in one of the plants harvested nine days after inoculation. The section in plate $1 A$ was made slightly above the level of figure $1 C$. It shows a ring of bundles formed by the traces of the foliage leaves, but no cotyledons. The six large bundles, three to the left and three to the right of the figure, belong to the first two foliage leaves. Of the four bundles appearing above in the ring, the three larger ones to the right belong to the third leaf, while the double bundle to the left is a young trace of the fifth leaf. The trace of the fourth leaf is located below in the ring. The traces of the fourth and fifth leaves contain no xylem, but the median bundle of the third leaf has two xylem elements. The viru i was introduced through the first cotyledon which was facing the third and fifth leaves in the plant. Primary hyperplasia appears in all bundles, including those that contain no xylem, but secondary necrosis and secondary hyperplasia are evident only in the traces of the two first leaves, in the two bundles which were nearest the inoculated cotyledon.

The section in plate $1 B$ was taken below the insertion of the cotyledons and, like figure $1 H$, shows the traces of the two cotyledons (above and below) and of the two first foliage leaves (to the left and right). The trace of the inoculated cotyledon appears above in the ring. The phloem of this cotyledon and of the first two leaves shows primary 
hyperplasia, while the cotyledonary trace located below in the figure is free of symptoms.

In another experiment, older plants having from two to four foliage leaves were used, and the site of inoculation was varied. Most specimens were examined in fresh freehand sections two to five days after the external symptoms appeared. In this second set of plants the localization of phloem degeneration was more pronounced than in the first set containing the younger plants because the hyperplastic tissue was more prominently developed.

The relation between the appearance of the first internal symptoms in the hypocotyl and the position of the inoculated leaf in the older plants may be briefly summarized as follows: If one of the two cotyledons or one of the two first leaves is inoculated in a plant having two foliage leaves, hypertrophy and hyperplasia develop first in the innermost ring (fig. $2 L$ ) in the sectors directly connected with the inoculated leaf or adjacent to its trace. In a plant in which the first cotyledon was inoculated, the initial hyperplasia was observed in the sectors $a$ and $h$ (fig. $2 L$ ) of the inner ring; and the external symptoms were first noted in the third leaf (compare $K$ and $L$ of fig. 2). An inoculation of the first leaf caused the first hyperplasia to develop roughly in sectors $c$ and $d$ (fig. $2 L$ ) of the first ring. When the second leaf was inoculated, the opposite side was affected. In somewhat larger plants, having three to four foliage leaves, the initial internal symptoms may develop in both rings almost simultaneously when one of the three first leaves is inoculated.

\section{DEGENERATION IN THE PRIMARY ROOT AND ITS RELATION TO SIEVE TUBES}

Structure of Healthy Root Tips.-The principal features of the primary structure of the taproot have been described by Seeliger (1919) and Artschwager (1926). The tips of lateral roots show the same primary structure as the taproot of a seedling.

Figure $3 H$ shows a diagram of a longitudinal section of a root tip. The central region represents the stele where the primary vascular tissue and the pericycle differentiate. It is surrounded by the cortex, whose innermost layer specializes as the endodermis. The cortex is covered by the epidermis and the apex of the root by the rootcap. As was shown by Seeliger (1919), the three main regions-the stele, the cortex, and the epidermis - originate from three distinct regions of the primary meristem-the plerome, the periblem, and the dermatogen, respectively. The rootcap arises from the dermatogen.

Two protophloem sieve tubes which appear about $0.4 \mathrm{~mm}$ from the 
growing point are the first vascular elements to differentiate in the stele. They develop adjacent to the pericycle on opposite sides of the stele (fig. $4 \mathrm{~A}$ ). The two elements often differentiate simultaneously, but sometimes one is somewhat slower. In occasional triarch roots three sieve tubes differentiate simultaneously.

The sieve tubes of the metaphloem arise in deeper layers of the procambium strand than the protophloem elements, so that some parenchyma cells lie between these sieve tubes and the pericycle (figs. $4 B, 5 A$ ).

The primary xylem is usually diarch. Two groups of protoxylem elements develop adjacent to the pericycle on opposite sides of the stele between the protophloem sieve tubes (fig. $4 B$ ). They appear $1 \mathrm{~mm}$ or more from the growing point, farther than the protophloem sieve tubes. The metaxylem elements differentiate, centripetally from each protoxylem group (fig. $5 A$ ). In the seedling root additional metaxylem elements differentiate centrifugally from the first ones (Seeliger, 1919). This stage of root development was observed in seedling roots but is not shown here. The procambial cells located between the primary xylem and the primary phloem differentiate into the normal primary cambium (Artschwager, 1926, fig. $16 \mathrm{~A}$ ).

The pericycle in a transverse section of a primary root is represented by one layer of cells surrounding the stele (figs. $4 A$ and $B$, and $5 A$ ).

The time of development of the endodermis probably varies considerably. According to Artschwager (1926, fig. 15 A), Casparian strips occur in the primary root at the level of the protophloem sieve tubes, whereas Seeliger (1919), in his figure 4, pictures them only where primary differentiation has been completed. In this study Casparian strips were first detected at the level of the first xylem elements in tips taken from lateral roots (fig. $4 B$ ). In seedlings grown on moist filter paper no Casparian strips were evident at the stage shown in figure $5 \mathrm{~A}$.

Vacuolation and enlargement of cortical cells occurs considerably closer to the growing point than the differentiation of the first protophloem sieve tubes. Some $40 \mu$ from the growing point, the outer cortical cells are conspicuously vacuolated and intercellular spaces are prominent among them. Then vacuolation becomes evident in the xylem region of the procambium strand so that the undifferentiated xylem plate, particularly the metaxylem region, may be made out some $90 \mu$ back of the growing point. Intercellular spaces now occur between the endodermal layer and that lying outside it. Vacuolation spreads from the xylem to the metaphloem region and from the outer cortical cells to the endodermis. The pericycle and the protophloem region are last to decrease in density. Pericyclic cells conspicuously vacuolate after the two proto- 
phloem sieve tubes have matured. At this level intercellular spaces appear between the endodermis and pericycle opposite the protoxylem region. After the maturation of the first xylem elements, intercellular spaces develop between the pericycle and cells of the central cylinder
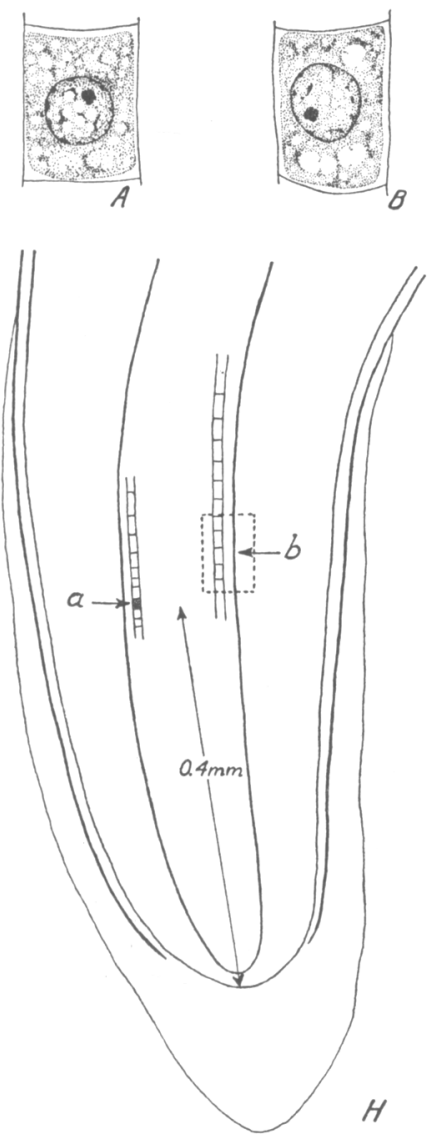

Fig. 3. $-A-G$, Protophloem sieve-tube elements in successive stages of development $(\times 1,197) ; H$, diagram of a longitudinal section of a root tip showing at $a$ the position of element depicted in detail in $E$, and at $b$ the position of the group of cells shown in $I(\times 72)$; I, longitudinal section of a portion of a root tip showing a protophloem sieve tube and adjacent cells $(\times 489)$.

near the xylem. Because of the regular arrangement of cortical cells, intercellular spaces in the cortex form long continuous canals leading almost to the growing point (fig. $3 I$ ).

The Primary Sieve Tubes.-The first two sieve tubes, being differentiated considerably in advance of other phloem elements, have been termed "protophloem" sieve tubes by Seeliger (1919). In its ontogeny 
the protophloem sieve tube undergoes changes like those occurring in the development of the primary sieve tubes in leaves (Esau, 1934b). Diagrams $A$ to $G$ of figure 3 represent a series of longitudinal sections of protophloem sieve-tube elements from one root tip, the cell in figure $3 A$ being closest to the growing point. The very young sieve-tube element depicted in figure $3 A$ resembles a procambial cell having abundant cytoplasm and a prominent nucleus. As the cell elongates, the vacuoles enlarge, and the nucleus shows a decrease in its staining capacity (fig. $3 B$ and $C$ ). In mature cells the nucleus is absent. The transformation from the condition shown in figure $3 C$ to that in figure $3 D$ frequently occurs very rapidly. The cells represented in these figures were lying adjacent to each other in the longitudinal row.

The cell in figure $3 D$ has the appearance characteristic of young sievetube elements. Its contents appear as a tangled mass of heavily stained threads connected with the parietal layer of cytoplasm. Sieve-tube plastids occur within the cytoplasm. The walls are thicker than in younger elements. Slime bodies were not found in the protophloem sieve tubes, but the threads represented in figure $3 D$ doubtless are similar to those observed when slime bodies are disintegrating in sieve tubes of the leaves (Esau, 1934b).

In many sections cells were found in stages intermediate between those shown in diagrams $C$ and $D$ of figure 3 . These had very pale nuclei, but the coarse network of strands was already present.

In elements farther from the tips than the one shown in figure $3 D$, the threads gradually disappear, but the plastids become more prominent. $E$ and $F$ of figure 3 show two such elements, between which one element has been omitted. The element in figure $3 E$ occupied a position in the root as is shown in figure $3 H$ at $a$. The elements still farther from the tip undergo elongation (fig. $3 G$ ). Two elements have been omitted between those of $F$ and $G$ of figure 3 , so that the latter represents the seventh cell from the young sieve tube having a nucleus shown in figure $3 C$. The elongated element contains little cytoplasm, and the few large plastids do not stain deeply. In such elements the plastids often appear clumped in the lumen of the cell (fig. $3 I$ ) and show signs of disintegration. They enlarge, stain faintly, and finally disappear as discrete structures. The old protophloem sieve tubes suffer considerable stretching in the more mature portion of the root; and when secondary growth occurs, they are crushed and obliterated.

Because of the changes in the protoplast described above, mature protophloem sieve tubes become strikingly conspicuous among the surrounding meristematic cells, which have comparatively dense protoplasts and prominent nuclei. Figure $3 I$ shows the difference in the stain- 
ing capacity of the contents of the protophloem sieve tube and of the adjacent cortical, pericyclic, and procambial cells. These elements occurred at $b$ in figure $3 H$. The protophloem sieve tube also tends to round off soon after the disintegration of the nucleus and threads, so that it appears distended (fig. $4 A$ ). In the more mature region these sieve tubes are less conspicuous, because they become surrounded by vacuolated cells.

As the protophloem sieve tubes have comparatively thin walls, the sieve plates are difficult to recognize in material treated with the usual killing fluids. The mitochondrial bichromate fixing solution, however, gave satisfactory results in this respect. By the use of it, sieve plates were clearly recognized in protophloem elements. Such plates occur in elements as young as the one shown in figure $3 \mathrm{C}$. Sieve plates were not drawn in figure 3 because this material was treated in the ordinary way and the plates were not discernible.

Companion cells apparently are not associated with every element of the protophloem sieve tubes. In some cases the cell lying adjacent to this element and toward the center from it (fig. $4 A$ ) shows the characteristics of a companion cell. It appears to arise from the same cell as the sieve-tube element, and retains its cytoplasm and nucleus after primary differentiation is completed. Such cells may occur on any side of the protophloem sieve tube. Figure $3 I$ shows in longitudinal section four companion cells associated with two of the lower protophloem sievetube elements.

More frequently, however, none of the cells lying adjacent to the sieve tube can be interpreted as companion cells. The cells lying adjacent and toward the center from the two protophloem elements may develop sieve plates and sieve-tube plastids and lose their nuclei. No companion cells are associated with the protophloem sieve tubes in figures $4 \mathrm{~B}$ and $5 \mathrm{~A}$.

In the more mature region, where the cells are much elongated and highly vacuolated, appear metaphloem sieve tubes-narrow elements, considerably longer than those of the protophloem. Being surrounded by elongated vacuolated cells, they are less conspicuous among other cells than are the protophloem sieve tubes. They show, however, the usual characteristics of sieve tubes.

In the transverse section shown in figure $4 B$, the metaphloem sieve tubes appear as groups of comparatively thick-walled cells adjacent to the protophloem sieve tubes and one layer of cells removed from the pericycle. Two similar groups of metaphloem sieve tubes are shown in figure $5 \mathrm{~A}$ but new metaphloem sieve tubes are differentiating to the right and left of each of the earlier groups. The divisions that may be 
observed here result in the formation of sieve tubes and companion cells. The earlier metaphloem sieve tubes, họwever, are not associated with cells that could be interpreted as companion cells.

Ontogeny of the Diseased Root Tips.-The relation between phloem degeneration and the differentiation of the first sieve tubes in the primary root was briefly noted in a previous paper (Esau, 1934a). The pathologic changes are first localized in cells lying around the two first protophloem sieve tubes and later spread farther, causing marked abnormalities in the structure of the stele of the primary root.

Sections $C-F$ of figure 4 show successive stages of development of the stele of a diseased primary root. They represent semidiagrammatic drawings of transverse sections of different root tips from the same plant. The stippling was used to bring out the cells in which degenerative changes were clearly evident; when heavier it indicates a more advanced stage of degeneration.

The section in figure $4 C$ was made at the level where the two protophloem sieve tubes had fully differentiated. They were in a stage similar to that of the normal element in figure $3 E$. Each sieve tube is surrounded by five cells, the two large ones belonging to the pericycle. To the left in the figure, three cells adjacent to the sieve tube showed hypertrophy of nuclei. To the right, the cells surrounding the sieve tube had coarsely granular and heavily stained protoplasts.

The degeneration, which in figure $4 C$ involved only cells adjacent to the sieve tubes, had in figure $4 D$ spread to cells at a greater distance, involving more cells of the pericycle and phloem, but no cortical cells.

Figure $4 E$ and $F$ shows two later stages in the development of diseased root tips. Cells in the stage of primary necrosis surround the protophloem sieve tubes, which are themselves filled with dead cytoplasm. The thick-walled cells toward the center from the protophloem in figure $4 E$ and $F$ represent the primary hyperplastic tissue that occupies the position of the metaphloem. As shown by figure $4 F$, hyperplasia has extended to certain pericyclic cells. They have divided and their daughter cells are developing sieve-tube characteristics. Casparian strips are absent in this root although its xylem is farther developed than that in the normal root shown in figure $4 B$. The inner cortical cells near the protophloem sieve tubes show some hypertrophy.

When degeneration is very severe, primary hyperplasia is more extensive than is shown in figure $4 F$ and may involve the inner cortical layer. Such a case is shown in figure $5 \mathrm{~B}$. Here the two protophloem sieve tubes are filled with dead cytoplasm. The lower sieve tube is surrounded by cèlls in the stage of primary necrosis which has even involved one cortical (endodermal) cell. Primary hyperplasia near the lower sieve 


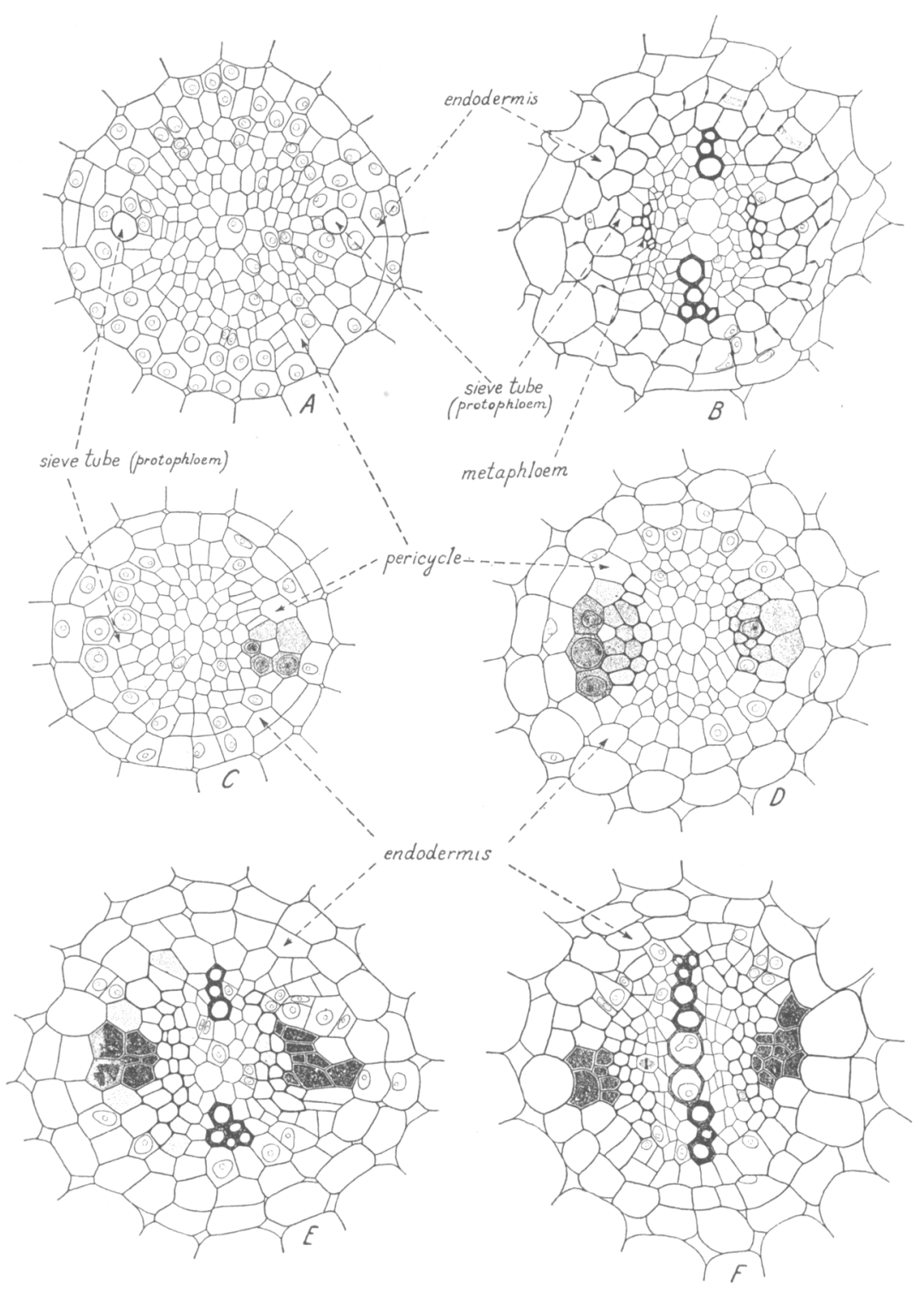

Fig. 4.-Transverse sections of healthy, $A$ and $B$, and diseased, $C-F$, root tips in different stages of development. Degenerating cells are marked by stippling. $($ All $\times 298$. $)$ 


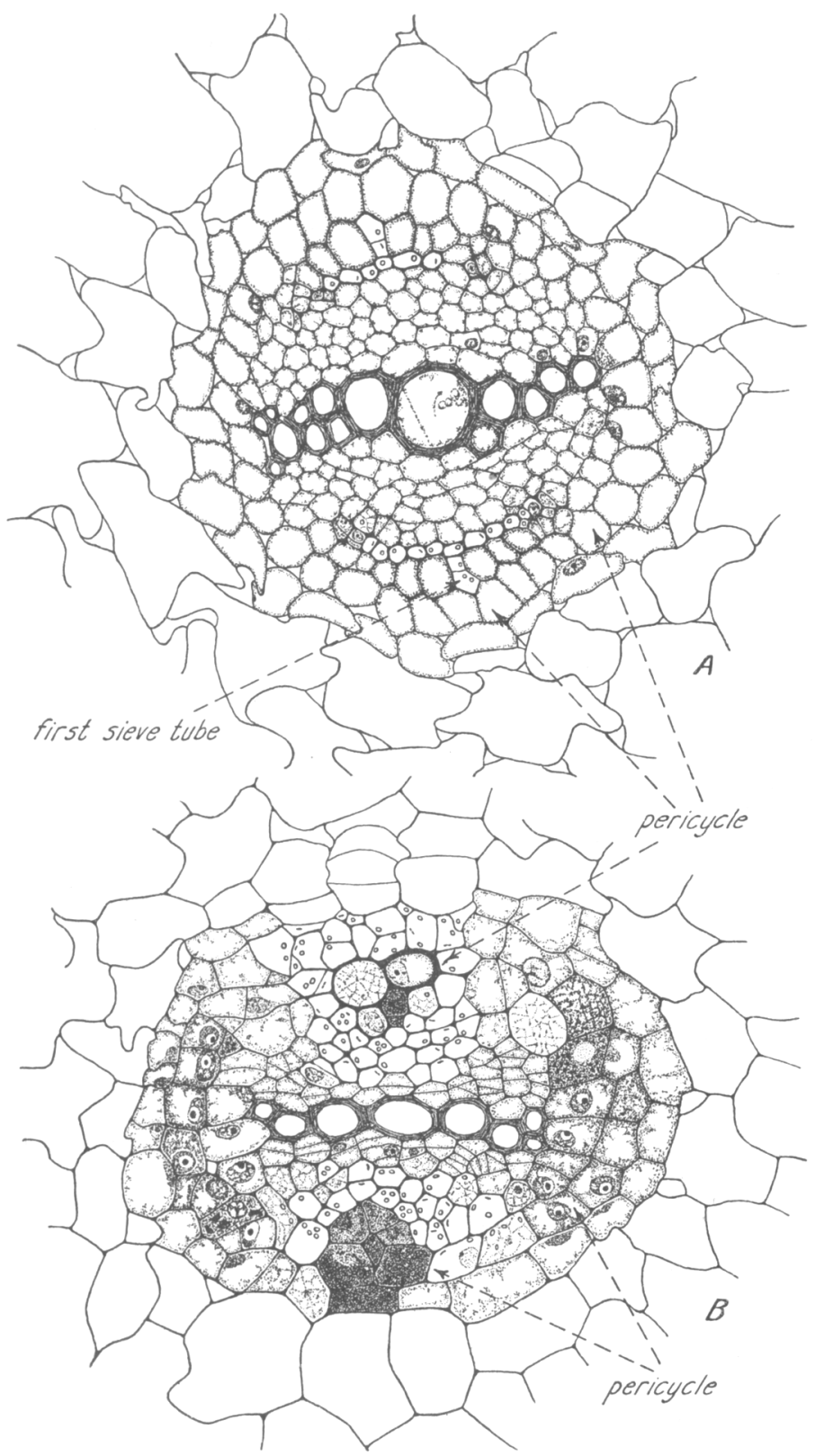

Fig. 5.-Transverse sections of root tips showing more advanced - primary development than figure 4: $A$, tip of taproot of a healthy seedling; $B$, tip of lateral root of a diseased plant. Cells marked with circles and rods are sieve tubes. (Both $\times 329$.) 
tube has given rise to sieve tubes within the phloem and pericyclic regions. The sieve tubes contain plastids indicated as rods and circles. Other contents of the mature sieve tubes were omitted. Adjacent to the upper protophloem sieve tube, the hyperplastic tissue is more extensive and involves also the inner cortical layer. The upper sieve tube, as well as one cell next to it, shows necrosis. Two pericycle cells near this sieve tube have very thick walls. One of them, the larger, shows a network of strands and is developing into a sieve-tube element.

In less severe cases of degeneration the pericyclic cells at the protoxylem points seem to remain free of abnormalities, but in the case shown in figure $5 B$ these cells showed pathologic changes. A comparison of these cells with the healthy pericyclic cells in figure $5 \mathrm{~A}$ shows a striking difference between the two groups of cells. All these pericyclic cells in the diseased root have darkly stained cytoplasm, coarse in structure. One cell in the lower left corner contains inclusion bodies (shown in black). In the upper right-hand corner the limit between the pericycle and the inner cortical layer is not clear because of irregular divisions that have occurred in this region. Three large cells in this region show changes very characteristic of cells affected by curly top. One has very dense coarsely granular cytoplasm with a small but prominent vacuole. The second cell has a coarse network of strands filling its lumen, whereas the third cell contains finer threads.

Figures $4 E$ and $F$, and $5 B$ show that the protophloem sieve tubes contain dead protoplasts. This phenomenon has been frequently observed. Sometimes dead material occurs in the youngest elements, sometimes in the older ones. It also may happen that one of the protophloem sieve tubes is necrotic, while the other remains clear like healthy elements. A necrotic sieve tube may be surrounded by other necrotic cells (fig. $5 B$, below; fig. $4 E$ and $F$ ), or it may be accompanied by cells showing other signs of degeneration (fig. $5 B$, above).

The degeneration of cells surrounding the protophloem sieve tubes may occur simultaneously on both sides of the root, but it also may be more pronounced on one side than on the other. Frequently degeneration is very marked in connection with one of the sieve tubes at the level of the first mature element, whereas it becomes perceptible at a higher level in connection with the other sieve tube. This seems to indicate a lack of uniformity in distribution of the injurious agent. The same conclusion could be drawn from the fact that root tips taken from one plant may vary considerably in degree of phloem degeneration.

Sugar-beet plants may be killed by curly top if infected while very young. Frequently, however, they survive the attack and live for sev- 
eral months. They may be carried over into the second year of growth and may then continue to produce new leaves. They may even develop seed stalks, although, in susceptible strains, both leaves and stalks are more or less dwarfed. Obviously, the meristematic activity at the growing point of the diseased shoot may continue for a long time; but it is partially inhibited, and the resulting organs are hypoplastic.

The growing point of diseased roots, however, appears to be frequently destroyed. Observations in the field show that severely diseased beets have a very short taproot decayed at the tip. On such roots numerous laterals develop from tissue regions where growth and division of cells have not yet ceased.

Whether or not such degeneration is a result of curly-top infection is problematical. The scanty cytological studies made so far do not permit a discussion with regard to the effect of the disease upon growing points. Abnormalities characteristic of the degenerating phloem, such as hypertrophy, hyperplasia, inclusions, and certain other features of protoplast degeneration have not been observed in cells of apical meristems.

The slow apical growth in curly-top plants suggests that meristematic cells of healthy and diseased plants differ in their physical and chemical organization. In diseased root tips differentiation of cells occurs closer to the growing point than in the healthy roots, so that the first mature protophloem sieve tube may occur $0.2 \mathrm{~mm}$ from the apical meristem. Xylem also matures closer to the tip than in disease-free roots.

The low rate of growth, however, may be a result of impaired nutrition, that is, a secondary effect of the disease, and does not necessarily indicate the presence of virus in the growing points.

The Degenerating Cells.-Rawlins ${ }^{5}$ has described cell degeneration in the region of maturation of diseased root tips of sugar beets. He found that the pericycle and the cells inside it undergo degenerative changes and that certain cells develop characteristic inclusions. He also noted that cells in early and late stages of degeneration could be found side by side in the younger as well as in the more mature regions of the root, so that the sequence of events in the degenerating cells could not be recognized by examining progressively older parts of the root. The following description substantiates Rawlins' observations, but adds more details concerning cell degeneration.

The affected cells vary greatly in the appearance of their protoplasts and at the first examination suggest that degeneration follows no definite course. The existence of a definite spatial relation between the sieve

5 Rawlins, T. E., Cytology and other studies of curly-top disease of the sugar beet. $49 \mathrm{p}$. Thesis for the degree of Doctor of Philosophy, University of California, 1926. (Typewritten.) Copies on file in the University of California Library. 
tubes and the degenerating cells enables one, however, to recognize certain regularities in the pathologic process.

Prominent among degenerating cells are those that show complete disorganization of the protoplast and undergo primary necrosis. Then there are many cells that at first show more or less pronounced pathologic changes, but later develop into rather thick-walled elements with sieve-tube characteristics. Less profoundly affected cells also occur and some of them may, in mature state, be similar to cells that showed no obvious signs of degeneration. It is not intended to give a complete description of the degenerating cells but to bring out the more common characteristics that assist in interpreting the relation of the protophloem sieve tubes to the spread of degeneration. This description is made on the basis of material killed in the chromo-acetic-formalin mixture, except when otherwise specified.

In cells undergoing most severe degeneration, frequently followed by death, the cytoplasm appears coarsely or finely granular or reticulate or very smooth and almost amorphous in texture, but stains deeply in all cases. As compared with normal cells, the cytoplasm is more dense and the vacuoles are often very sharply delimited. Large lumps or small granules may be abundant in such cells (fig. $6 H$ ) or discrete structures may be lacking in their cytoplasm. The nuclei degenerate. Sometimes they enlarge considerably, appearing to become vacuolate, and their chromatin occurs at the periphery in the form of coarse deeply stained threads or lumps. Sometimes nuclei fail to undergo hypertrophy. Some degenerating nuclei show no discrete structures and their contents appear smooth and amorphous.

Cells which develop into abnormal sieve tubes may, in their early stages of development, show as dense and as darkly stained cytoplasm as those that are subject to primary necrosis. Or they may have only slightly darker protoplasts than those of the normal cells. Later the contents of these cells are resolved into a parietal layer of cytoplasm, containing sieve-tube plastids; and a more or less coarse network of strands filling the lumen (figs. $6 F$ and $5 \mathrm{~B}$, above). The nuclei disappear with or without a preceding hypertrophy. Usually the nuclei in such cells seem to lose their contents, are faintly outlined (fig. $6 F^{\prime}$ ), and then cease to exist as discrete structures. The network later disappears and the cells become similar to normal sieve tubes in their internal structure. Sieve plates have been clearly recognized in such cells by the use of the mitochondrial bichromate killing fluid.

The presence of an abnormal number of sieve-tube elements in the degenerating phloem indicates that certain cells develop into them instead of parenchyma. Figure $5 B$ shows that sieve tubes extend much 
closer to the xylem than in the normal root tip in $5 \mathrm{~A}$. In some diseased root tips sieve tubes differentiate directly adjacent to the xylem so that no cells are left to give rise to the centrifugal metaxylem and to the cambium. Pericyclic and cortical cells also may differentiate into sieve tubes. Figure $6 \mathrm{~F}$ shows a young sieve tube derived from a pericycle cell which occurred near a protophloem sieve tube. In contrast, a normal pericycle cell which was located near the protoxylem in the same root is shown in figure $6 G$. When sieve tubes develop from procambium cells centripetally from the protophloem sieve tubes, as in figure $5 B$, they are usually elongated (fig. $6 \mathrm{~N}$ ) and can hardly be distinguished from normal metaphloem sieve tubes (fig. $6 \mathrm{M}$ ). When, however, pericyclic or cortical cells give rise to sieve tubes, these are short (fig. $6 \mathrm{~F}$ ) and of ten of irregular shape, because of many oblique longitudinal divisions.

A frequent characteristic feature of the diseased cells, whether they do or do not undergo primary necrosis, is the development in the cytoplasm of more or less large bodies. They have been referred to as "inclusions" by Rawlins ${ }^{6}$. He has described two types of inclusions: the $x$ type, a densely stained amorphous body (fig. $6 B$ ), and the $y$ type, a lightly stained spherical body containing many heavily stained globules (fig. $6 D$ and $K$ ). He suggested that the $y$ body is made up of $x$ material that has accumulated in the vacuoles.

According to the present study, the $x$ and $y$ types of body appear to be one kind of structure in two different stages of development. In the younger portion of the root tip the $x$ bodies are common, whereas in the more mature region the $y$ type predominates. Where primary necrosis is not taking place, the $x$ bodies occur in cells showing less advanced stages of protoplast degeneration than those containing $y$ bodies. Types transitional between $x$ and $y$ (fig. $6 C$ ) have been frequently noted. Very probably, therefore, the $x$ type of body changes over into the $y$ type in more mature cells, so that the use of two terms, " $x$ body" and " $y$ body," seems inappropriate. In the following, both bodies will be referred to as "inclusion bodies" or "intracellular inclusions."

In beet-root tips affected by curly top, the inclusion bodies have been observed most commonly in cells lying close to the protophloem sieve tubes. Frequently they may be recognized in very young undifferentiated pericycle and phloem cells at the level where the youngest protophloem sieve tubes are located. In other cases they first develop in somewhat older cells associated with more mature sieve-tube elements. They may be very abundant in some root tips and scarce in others.

6 Rawlins, T. E. Cytology and other studies of curly-top disease of the sugar beet. $49 \mathrm{p}$. Thesis for the degree of Doctor of Philosophy, University of California, 1926. (Typewritten.) Copies on file in the University of California Library. 

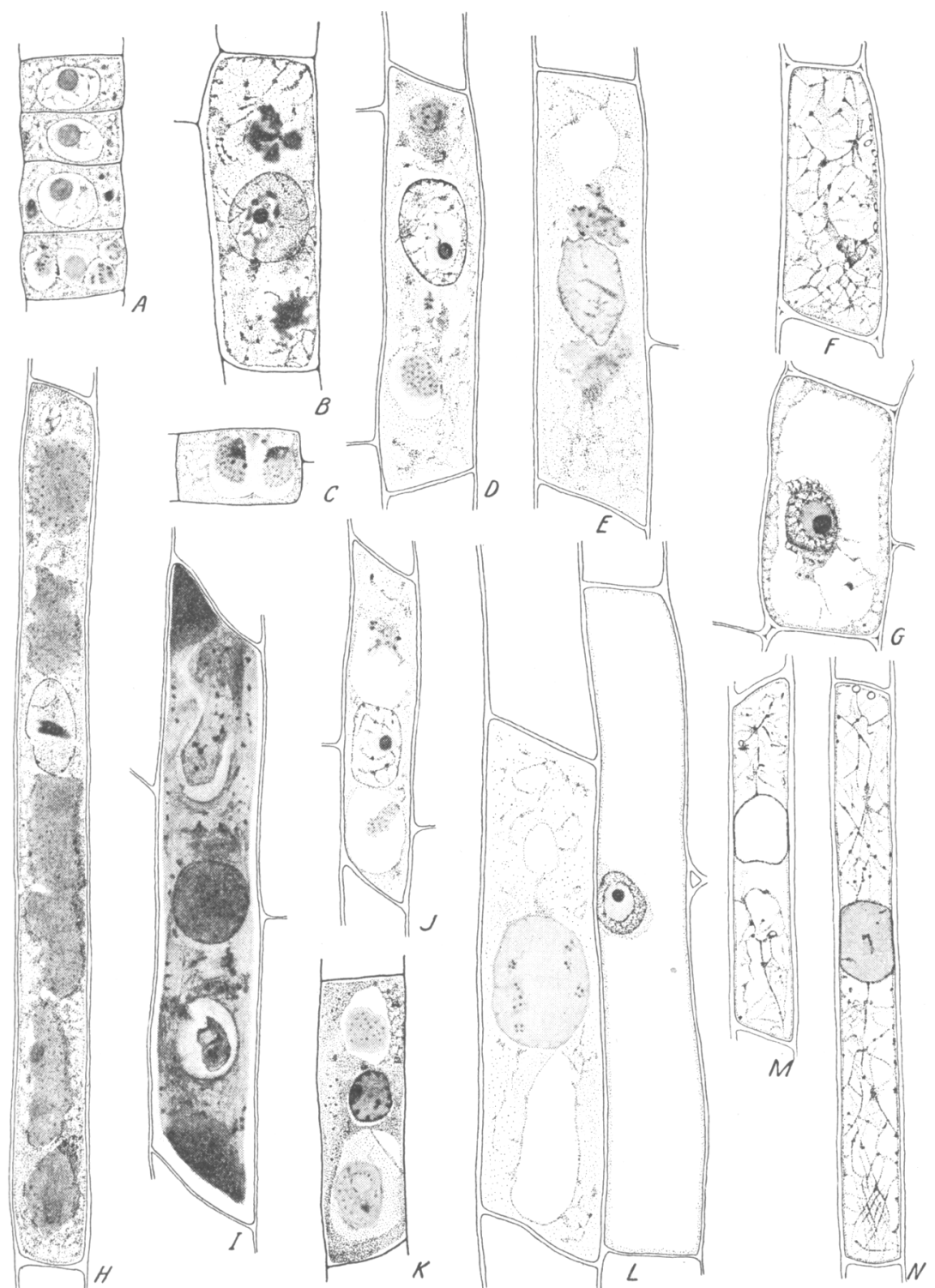

Fig. 6.-Longitudinal sections of healthy and degenerating cells from the phloem of root tips: $A-E$ and $H-K$, cells with inclusions; $I$, cell undergoing primary necrosis; $F$, young sieve tube derived from a diseased pericycle cell; $G$, a normal pericycle cell from a diseased root tip; $L$, a pericycle cell with a hypertrophied nucleus (left) $M$, healthy young metaphloem sieve tube; $N$, young sieve tube from metaphloem of a diseased root. (All $\times 961$.) 
In cells that do not undergo primary necrosis, the inclusion bodies pass through stages of development and disintegration. Observations on cells fixed with the chromo-acetic-formalin mixture and stained with Heidenhain's hematoxylin suggest the following sequence of events. In young cells closely associated with the protophloem sieve tube, small, darkly stained bodies become perceptible in the cytoplasm (fig. $6 \mathrm{~A}$, uppermost cell). These bodies enlarge and frequently increase in number ( $6 A$, two cells in the middle). Compact and amorphous, they resemble the nucleolus or the chromosomes in their avidity for cytoplasmic stains. They may attain a considerable size before disintegrating (fig. $6 B$ ) or may remain small. In the latter case, frequently, they are well rounded off (fig. $6 \mathrm{~A}$ ); but the larger bodies are variously lobed (fig. $6 \mathrm{~B}$ ) and sometimes resemble clumps of chromosomes as the latter appear in telophase. In exceptional cases the bodies are long, slender, and sinuous.

The stage of development at which the body is compact and darkly stained is of short duration. Even in fairly young cells the amorphous bodies may become resolved into a conglomerate of small dark globules or granules imbedded in a lighter-stained mass, gray or yellowish gray and finely granular (fig. $6 \mathrm{~A}$, lowermost cell, and $D$ ). This mass appears very finely reticulate when the mitochondrial bichromate killing fluid is used. One frequently encounters loosely aggregated bodies that still show a compact mass of material at one end (fig. $6 C$ ). The aggregations continue to loosen (fig. $6 \mathrm{E}$ ) until the entire material becomes dispersed in the vacuole (fig. $6 J$ ).

Material resembling disintegrating bodies may occasionally be observed within the hypertrophied nucleus (fig. $6 \mathrm{~L}$ ), which itself resembles a large vacuole. When the cells are subject to primary necrosis, the bodies may often be distinguished until the contents of the cell show complete disorganization (fig. $6 \mathrm{I}$ ) ; and often they retain their compact structure until the protoplast dies.

Disintegration of intracellular bodies has been observed also in the aucuba mosaic in Solanum sp. According to Sheffield (1931), who has made observations on living cells, the inclusions in this disease crystallize out, and the resulting protein crystals disperse throughout the cell.

Frequently the disintegrating body in curly-top beets is well rounded off (fig. $6 \mathrm{D}$ ) and sometimes it appears to have a membrane (fig. $6 \mathrm{~K}$ ). Rawlins, ${ }^{7}$ observing such membranes enclosing $y$ bodies, interpreted them as derived from the vacuole in the host cytoplasm. Woods (1933)

7 Rawlins, T. E. Cytology and other studies of curly-top disease of the sugar beet. $49 \mathrm{p}$. Thesis for the degree of Doctor of Philosophy, University of California, 1926. (Typewritten.) Copies on file in the University of California Library. 
found that the intracellular bodies associated with ring-spot of tobacen may or may not be limited by a membraneous layer. Sheffield (1931), however, studying the aucuba mosaic inclusions in living condition, found no indication of a limiting membrane. The findings of these workers and the present observations suggest that membranes occurring around inclusion bodies in fixed material are artifacts. Probably, however, under certain conditions-for example, when the bodies occur in the vacuole - there is between the body material and the enclosing medium a limiting layer of the same nature as that which exists between the cell sap and the cytoplasm. On fixation this limiting layer may appear as a membrane.

The compact inclusion usually occurs in the cytoplasm (fig. $6 \mathrm{~A}$ and $B)$; but the disintegrating body is found most frequently within the vacuole (fig. $6 A, D, J$, and $K$ ), although occasionally in the cytoplasm (fig. $6 \mathrm{E}$ ).

The bodies very commonly occur in pairs (fig. $6 B, D, E, J$, and $K$ ). In the elongated cells, apparently, the inclusion bodies develop on both sides of the nucleus and remain in their respective positions. There may be, however, only one body in a cell, especially in the younger and shorter ones; or the inclusions may be so numerous that the contents of the cell appear to be divided into irregular darkly stained lumps. If such cells do not undergo primary necrosis, the numerous bodies disintegrate and later practically fill the cell with their debris, which is yellowish gray and contains dark granules (fig. $6 H$ ).

The inclusion bodies may lie close to the nucleus, sometimes even deforming it. In most cases, however, they are not associated with the nucleus; and, judging from this study, are not derived from it. As mentioned before, the nucleus may contain material that resembles disintegrating inclusion bodies (fig. $6 \mathrm{~L}$ ). Sometimes the nucleolus breaks down into a yellowish gray mass like that occurring in dispersing inclusions, except that the dark granules are absent.

In their early stages of development, inclusion bodies have a certain resemblance to slime bodies in young sieve tubes. But slime bodies never show structure comparable to that of the disintegrating inclusion, and they have a less pronounced avidity for dyes than the compact bodies. Slime bodies do not attain the size of the largest inclusion bodies and do not occur in pairs.

\section{PHLOEM DEGENERATION IN THE FLESHY TAPROOT}

The Healthy Taproot.-The normal ontogeny of the fleshy taproot has been described by other workers (Artschwager, 1926; Seeliger, 1919) and was reviewed in a previous paper (Esau, 1933). Plate 2 shows the 
fleshy part of a healthy beet root in a transverse section made at the level where the oldest lateral roots depart. The traces of these roots are darkly stained. The core of the root includes the primary xylem and the secondary tissues of the first or normal vascular ring. In this figure the primary xylem is distorted because of the subsequent growth of parenchyma cells in this region. The main portion of the fleshy body is made up of the tissues that have differentiated from the layers of anomalous secondary cambium. In transverse sections these tissues are arranged in concentric rings, each containing cambium, xylem, phloem, and storage parenchyma. Xylem and phloem form collateral bundles, separated from each other by parenchyma. The inner rings are older and thicker than the outer. The vascular bundles of one ring are connected with others in the same ring and also anastomose with the bundles of the adjacent rings.

The results of two experiments will be used as a basis for the discussion of phloem degeneration in the fleshy taproot. In one experiment, plants of the same age were inoculated at successive intervals, but were harvested on the same date. The course of phloem degeneration and some secondary effects of the disease upon root development were observed in these plants. In the second experiment, plants of the same age were inoculated at a given date and harvested successively at different dates. Localization and spread of phloem degeneration in the secondary rings were studied in this set of plants. The results of these experiments were confirmed by other tests, but as they give a complete picture of phloem degeneration by themselves, no further experiments will be described.

Course of Phloem Degeneration in the Fleshy Root.-Phloem degeneration in the root follows the same course as in the leaves (Esau, 1935). The peculiar structure of the normal fleshy root, however, justifies a brief description of the disease as affecting this organ.

When secondary growth occurs in the fleshy taproot, phloem degeneration spreads to the newly developing rings; but, as previously noted (Esau, 1934 a), apparently normal sieve tubes differentiate first in these new rings, and then the characteristic pathologic changes develop close to these elements. Figure 7 illustrates the important stages in the development of healthy $(A, B)$ and of diseased $(C-F)$ phloem in the secondary rings of the taproot. The cell contents have been omitted in these drawings, but oblique lines were used to bring out normal and abnormal sieve tubes and stipples to mark the companion cells. Cells shown in black underwent necrosis.

Figure $7 A$ shows a portion of a healthy root taken near the periphery. The cambium of the youngest ring is discernible above in the picture. One sieve tube with two companion cells has been cut off. The 
cambium of the adjacent older ring, shown below in the same picture, has given rise to several sieve tubes and companion cells. No xylem has differentiated from these two cambia.

Figure $7 B$ depicts some phloem of a more mature secondary ring, the fourth from the periphery. The xylem is not included in this pic-
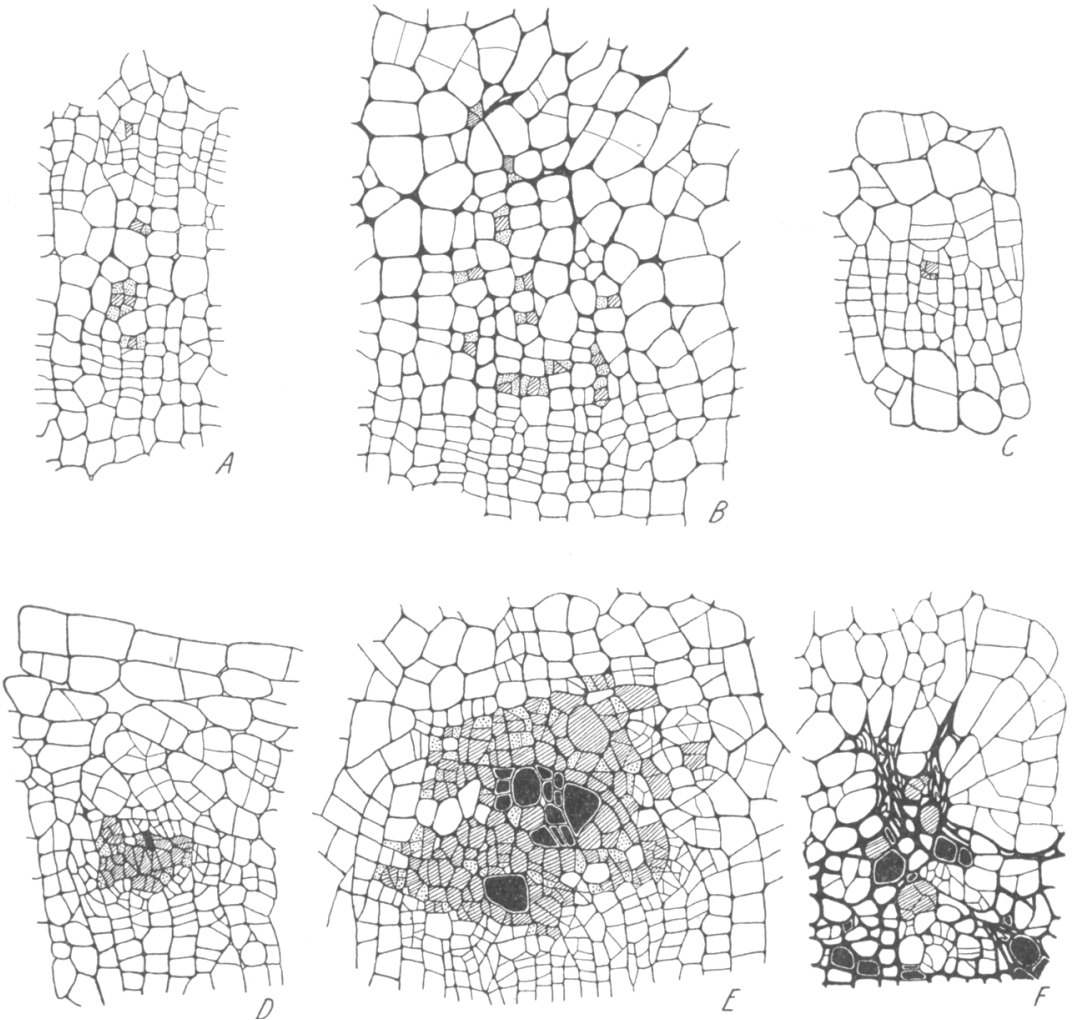

Fig. 7.-Transverse sections through phloem of fleshy taproots: $A-B$, healthy phloem ; $C-F$, diseased phloem. Oblique lines indicate sieve tubes; stipples, the companion cells. $($ All $\times 157$.)

ture. The cambium is at the lower edge, then follows the functioning phloem and, at the top of the picture, are the old sieve tubes and companion cells that are undergoing obliteration.

Figure $7 C$ represents a portion of cambium of the outermost ring of a diseased root. Two apparently normal sieve tubes have differentiated but no degeneration is perceptible in this young phloem. The section in figure $7 \mathrm{I}$ ) was taken also from the outermost ring of a diseased root, but shows more mature phloem than figure $7 \mathrm{C}$. Primary hyperplasia has given rise to numerous abnormal sieve tubes. One cell in this group underwent primary necrosis and is shown in black. 
Figure $7 E$ shows diseased phloem comparable in age to the healthy in $7 \mathrm{~B}$. A group of cells underwent primary necrosis while a strikingly large number of primary hyperplastic cells developed into abnormal sieve tubes.

In figure $7 F$ the hyperplastic tissue has collapsed (secondary necrosis) and some parenchyma cells in the upper right-hand corner have enlarged and divided (secondary hypertrophy and hyperplasia) so that the space left by the collapsed cells is now occupied by new thinwalled parenchyma cells. Lieakage of material from collapsed phloem into intercellular spaces, as described in leaves (Esau, 1933) was found in roots also, but is not shown in the figures.

More and less severe phloem degeneration may be obtained in the fleshy root by varying the time of inoculation. If the plant is affected by the disease in a very young stage, it will usually show a more pronounced degree of phloem degeneration than a plant that becomes diseased at a later stage of development. Early infection, moreover, causes marked secondary effects, especially a stunting of the root.

Table 1 shows the results obtained with four plants that were inoculated on different dates but were harvested on the same day. In every case the leaf next to the youngest was inoculated.

As was to be expected, the plant that was youngest on the day of inoculation and which had harbored the virus for the longest period (plant 1 in table 1) showed most severe phloem degeneration. It also had the smallest diameter of root on the day of harvest.

The root diameter was determined just above the region of lateral roots; and two diameters were measured-the shortest and the longest. The number of rings was counted in the same region.

Plates 2 and 3 show for comparison a healthy section and two diseased sections, made below the level where the rings were counted. Plate $3 B$ was taken from the root of plant 1 ; plate $3 A$, from plant 2 . As the check plant (plate 2) was grown under similar conditions, the difference in size of the roots may be attributed to the stunting effect of the disease. The hyperplastic phloem in plate $3 \mathrm{~A}$ differs strikingly from the phloem in the healthy root, being arranged more compactly and staining more deeply. In plate $3 B$ the callus-like hyperplastic tissue that developed after the collapse of the degenerated phloem may be clearly recognized in the two older rings, particularly in the second. This tissue is composed of large thin-walled parenchyma cells which, in contrast to the primary hyperplastic tissue and to the necrotic lesions, stain faintly. On one side of this root was a large cavity, bordered by necrotic tissue. Obviously, this developed because death and collapse of 
TABLE 1

Description of Plants Used in the First Experiment

(Sown June 8, harvested September 16)

\begin{tabular}{|c|c|c|c|c|c|c|c|c|c|}
\hline \multirow{2}{*}{$\begin{array}{l}\text { Plant } \\
\text { No. }\end{array}$} & \multicolumn{2}{|c|}{ Inoculation } & \multicolumn{2}{|c|}{$\begin{array}{l}\text { Appearance of } \\
\text { symptoms }\end{array}$} & \multirow{2}{*}{\begin{tabular}{|c|} 
Days \\
from \\
inocula- \\
tion to \\
harvest
\end{tabular}} & \multicolumn{2}{|c|}{$\begin{array}{c}\text { Diameter of root } \\
\text { in millimeters }\end{array}$} & \multirow{2}{*}{$\begin{array}{c}\text { Number } \\
\text { of } \\
\text { rings* }\end{array}$} & \multirow{2}{*}{ Phloem degeneration } \\
\hline & Date & $\begin{array}{c}\text { Number } \\
\text { of } \\
\text { leaves }\end{array} \mid$ & Date & $\begin{array}{c}\text { Days } \\
\text { to } \\
\text { harvest }\end{array}$ & & $\begin{array}{c}\text { Short- } \\
\text { est }\end{array}$ & Longest & & \\
\hline 1 & July 7 & 4 & July 14 & 64 & 71 & 4 & 6 & 4 & $\begin{array}{l}\text { Most severe; secondary } \\
\text { necrosisandsecondary } \\
\text { hy perplasia promi- } \\
\text { nent in all rings con- } \\
\text { taining phloem }\end{array}$ \\
\hline 2 & July 16 & 6 & July 24 & 54 & 62 & 5 & 6 & 4 & $\begin{array}{l}\text { Primary degenerative } \\
\text { changes, including pri- } \\
\text { mary necrosis promi- } \\
\text { nent in all rings con- } \\
\text { taining phloem; occa- } \\
\text { sional secondary ne- } \\
\text { crosis and secondary } \\
\text { hyperplasia }\end{array}$ \\
\hline 3 & July 24 & 8 & Aug. 2 & 45 & 54 & 9 & 13 & 5 & $\begin{array}{l}\text { Primary hypertrophy } \\
\text { and pronounced pri- } \\
\text { mary hyperplasia in } \\
\text { all rings containing } \\
\text { phloem; primary ne- } \\
\text { crosis fuirly common }\end{array}$ \\
\hline 4 & Aug. 10 & 10 & Aug. 22 & 25 & 37 & 11 & 12 & 6 & $\begin{array}{l}\text { Primary hypertrophy } \\
\text { and pronounced pri- } \\
\text { mary hyperplasia in } \\
\text { all rings containing } \\
\text { phloem; occasional } \\
\text { primary necrosis }\end{array}$ \\
\hline Check & & $\ldots$. & & $\ldots$. & $\ldots .$. & 12 & 13 & 6 & \\
\hline
\end{tabular}
ring.

* Figures show number of rings with vascular elements; in each case there was an additional cambium

phloem were so rapid that healing through cell proliferations could not keep pace.

In less severely affected roots, in plants 3 and 4 of table 1 , the younger rings showed degeneration of the entire layer of phloem; but in the older rings, especially in the first, only the secondary phloem that was formed later was affected. The primary and the older secondary phloem had become obliterated in the normal manner.

No localization of symptoms in relation to the position of the inoculated leaf was recognized in this set of plants because phloem degeneration had time to spread to all parts of the root.

In this experiment the number of rings was not greatly reduced, the reason being that even the youngest plant was comparatively large, 
with four foliage leaves, on the day of inoculation. Plants inoculated at the cotyledonary stage may show greater differences from healthy plants.

A comparison of the healthy root section (plate 2) with the diseased ones (plate 3 ) shows that the latter have a smaller number of rings and a smaller width of individual rings. A pronounced difference appears also in the size of parenchyma cells, these being much larger in the healthy root. Frequently the xylem has thick heavily lignified walls in diseased roots (plate $3 A$ ).

TABLE 2

Description of Plants Used in the Second Experiment (Sown January 26, inoculated February 20)

\begin{tabular}{|c|c|c|c|c|c|c|c|}
\hline \multirow{2}{*}{$\begin{array}{l}\text { Plant } \\
\text { No. }\end{array}$} & \multirow{2}{*}{$\begin{array}{c}\text { Number of leaves when } \\
\text { inoculated }\end{array}$} & \multicolumn{2}{|c|}{$\begin{array}{l}\text { Appearance of } \\
\text { symptoms }\end{array}$} & \multicolumn{2}{|c|}{ Harvest } & \multicolumn{2}{|c|}{ Days to harvest } \\
\hline & & Date & Leaf & Date & $\begin{array}{c}\text { Number } \\
\text { of } \\
\text { leaves }\end{array}$ & $\underset{\substack{\text { inocula- } \\
\text { tion }}}{\text { From }}$ & $\begin{array}{c}\text { From } \\
\text { appearance of } \\
\text { symptoms }\end{array}$ \\
\hline 1 & 2, 3rd small ............. & Feb. 23 & third & Feb. 26 & 5 & 6 & 3 \\
\hline 2 & 2,3 rd very small..... & Feb. 26 & third & Feb. 28 & 4 & 8 & 2 \\
\hline 3 & 2,3 rd small $\ldots \ldots \ldots \ldots$ & Feb. 27 & fourth & Mar. 4 & 6 & 12 & 5 \\
\hline 4 & 2,3 rd very small............... & Feb. 27 & third & Mar. 7 & 6 & 15 & 8 \\
\hline 5 & 2,3 rd very small & Mar. 1 & fifth & Mar. 17 & 8 & 25 & 16 \\
\hline
\end{tabular}

Roots severely stunted from curly-top infection develop numerous laterals, which branch profusely upon emerging and appear crowded upon the small stunted taproot. Often the excessive proliferation of the laterals is accompanied by cushions of tissue or protuberances developing at the base of these roots. Plate $3 B$ shows such protuberances, which give the outline of the root an irregular appearance. The laterals seemingly arise from these protuberances but actually originate in deeper layers and connect with the rings of vascular tissue, frequently, however, only with the outermost. For comparison, the smooth surface of the healthy taproot, at the point where the laterals emerge, is shown in plate 2 .

The Spread of Phloem Degeneration in the Secondary Rings of the Root.-Five young plants were inoculated with curly top through the first foliage leaf and were harvested at different dates. Healthy check plants of similar age and size as the diseased were harvested at the same dates. Table 2 describes the treatment and development of the diseased plants.

In plant 1 , harvested 6 days after inoculation, advanced primary hyperplasia was readily discernible in the first ring below the trace attachment of the first leaf. Below the traces of the cotyledons and of 
the second leaf, the first ring showed no abnormal growth. The second ring also was apparently free from degenerative changes. The third ring had not yet developed.

In plant 2 , harvested 8 days after inoculation, primary hypertrophy and hyperplasia had spread laterally and vertically in the first ring, so that only the region below the trace of the second leaf remained free of abnormalities. Symptoms also appeared in the second ring on the inoculated side. On the side free from symptoms, the cambium of the third ring and a few phloem elements had developed; but no third ring had formed on the inoculated side. A section of the lower hypocotyl of plant 2 appears in plate 4 . The center is occupied by the pith, to the right and left of which the xylem of the two cotyledons may be recognized. The first ring of vascular tissue encloses the pith and the cotyledonary traces. The upper half of this ring (in the plate) was directly connected with the trace of the first-that is, the inoculated leaf; and the second leaf was attached on the opposite side. In the first and second rings the hyperplastic phloem on the inoculated side appears in the figure as a broad band of deeply stained tissue, strikingly different from the normal phloem on the lower side of the root. A portion of the third ring is perceptible in the lower half of the photograph, but on the inoculated side the third ring is absent. This section illustrates the combination of hypertrophy and hyperplasia with hypoplasia characteristic of virus-diseased plants. Abnormal growth and division of cells in the phloem are accompanied by a reduced development in other tissues.

In the third plant, harvested 12 days after inoculation, the situation was similar to that in the second, except that primary degeneration in the first two rings had spread farther laterally toward the side not inoculated. The third ring had a few phloem elements on the normal side, but showed no degeneration. On the inoculated side the third ring was present as an irregularly interrupted band of cambium.

In plant 4, harvested 15 days after inoculation, the first ring still showed absence of hypertrophy and hyperplasia in the region below the trace of the second leaf; but symptoms had spread almost throughout the entire second ring. The third ring was absent on the inoculated side but showed phloem degeneration on the opposite side. Primary and secondary necrosis and occasional secondary hyperplasia were observed in this plant.

In the fifth plant, harvested 25 days after inoculation, phloem degeneration appeared on both sides of the root, although it still was more pronounced on the inoculated side. The third ring was present only on 
the side not inoculated, and showed degeneration. Primary necrosis was pronounced in the root; and secondary degeneration had made progress, as compared with the root of plant 4 .

This experiment clearly shows that the internal symptoms are at first localized in parts of root and hypocotyl directly connected with the inoculated leaf; that phloem degeneration later spreads laterally in the rings-more rapidly in the younger than in the older; and that the development of the secondary rings of cambium is retarded on the side where phloem degeneration is most pronounced.

\section{DISCUSSION}

The curly-top virus spreads through the plant comparatively rapidly and, as Severin (1924) has shown, enters all the organs. If it were moving through any part of the vascular tissue it could penetrate the plant very rapidly, because the complex vascular system of the beet provides a very intimate connection among the different leaves and between the leaves and the root. The virus introduced into young and old leaves of young and older plants eventually spreads to all rings in the root, as evidenced by phloem degeneration in them.

In the early stages of infection, however, the symptoms of curly top are definitely localized. If this localization is viewed in relation to the development of leaf traces and their connections with one another and with the rings in the root, the distribution of the virus appears to depend on the phloem connections. Both the internal and the external symptoms first become perceptible in those parts of the plant which are nearest the inoculated leaf and which are directly connected with it by phloem tissue. Xylem does not seem to be concerned in this movement, because phloem degeneration occurs in those traces where no xylem has yet differentiated, and in the primary root, characteristic abnormalities develop in close association with protophloem sieve tubes below the level to which protoxylem reaches.

The observations on the localization of the initial symptoms in curlytop beets agree with Bennett's (1934) suggestion that phloem serves as a channel through which this virus is translocated within the plant.

Cells that undergo primary necrosis usually occur next to the protophloem sieve tubes. The inclusion bodies, though present in cells not in immediate contact with these elements, are most common in cells adjacent to them. One could explain such distribution of degenerative changes by assuming that the virus is translocated in the protophloem sieve tubes and thence penetrates the surrounding tissue. Cells nearest these elements would receive most of the virus and would suffer most 
severe degeneration, while cells farther removed would have a lower concentration of the injurious agent and less pronounced abnormalities.

In this connection the recent findings of Livingston and Duggar (1934) seem especially pertinent. These workers reported a method enabling them to withdraw the contents of individual cells and to determine the concentration of the virus therein. The tobacco mosaic virus showed the highest concentration in cells containing inclusions, and the authors suggest that "the inclusion bodies at least accompany the development of the virus agency in high concentration."

One might infer a relation between virus concentration and localization of inclusions from the observations of Woods (1933) on the ring spot of tobacco. He found that the intracellular bodies occurred only in the visibly lesioned areas within the necrotic rings, and that the cells in close proximity to the necrotic areas contained more inclusions than those some distance away. He failed to find these bodies in the normalappearing tissue outside the rings, either in primary or in systemic lesions.

The suggestion that cells showing most pronounced degenerative changes in curly top contain most virus should not be taken to mean that the virus concentration is the only factor determining the course of degeneration. Of several cells adjacent to the same protophloem sieve tube, one or more may be completely destroyed, whereas others develop into sieve-tube-like cells, even though they may contain inclusions in their early ontogeny.

On the basis of the present study, it remains an open question whether or not the virus reaches the growing point and causes its degeneration. The low rate of growth and occasional death of the growing point could be a result of deficient nutrition. Since phloem degenerates and even the protophloem sieve tubes may become necrotic, the channel through which food materials presumably move to the growing point may be affected and nutrition of the meristem may fail. The tissue may show hypoplasia or die of starvation.

Conceivably, on the other hand, the virus might occur in the growing point itself. If it moves in the protophloem sieve tubes, it is brought in the root to within about half a millimeter or less of the growing point. Should it "leak out" of the sieve tubes, it could probably reach the undifferentiated portion of the root.

According to Bennett (1934), the curly top virus occurs in very low concentrations in parenchyma outside the phloem. To explain this low virus content in beet parenchyma, he suggests that the virus either "does not pass out of the phloem or that it is very quickly inactivated 
by contact with normal cells of other tissues." The problem of the relation of the curly-top virus to tissues other than phloem is worthy of a detailed study.

\section{SUMMARY}

In the beet plant a close connection exists among the vascular traces of different leaves and between the leaf traces and the vascular rings in the root.

The external symptoms of curly top develop only in the young leaves.

These symptoms appear first in those young leaves that are most closely connected by phloem with the inoculated leaf.

The first internal symptoms also are strictly localized and develop in regions directly connected with the inoculated leaf.

Phloem degeneration may be initiated in traces containing no mature xylem, and in the primary root it appears before the protoxylem differentiates.

In the fleshy taproot, phloem degeneration first appears on the side from which the inoculated leaf diverges. Later the degeneration spreads laterally in each ring and from the older to the newly developing rings.

$A s$ in the leaves, phloem degeneration in the roots is initiated near the first sieve tubes and from here spreads to cells farther removed.

Bodies interpreted as intracellular inclusions commonly occur adjacent to the first sieve tubes from which the injurious agent seems to spread in the phloem. Less frequently they occur in cells farther removed from these sieve tubes. If cells containing inclusions do not undergo necrosis, these structures disintegrate.

Cells undergoing most severe degeneration undergo necrosis very early in their development. Less profoundly affected cells usually develop into elements having all the characteristics of sieve tubes.

The observations on localization and spread of symptoms in curlytop-diseased beets support the viewpoint that the curly-top virus is translocated in the phloem tissue, in particular in the mature sieve tubes. 


\section{LITERATURE CITED}

ARTSCHWAGER, E. F.

1926. Anatomy of the vegetative organs of the sugar beet. Jour. Agr. Research $33: 143-176$.

A VERY, G. S. JR.

1933. Structure and development of the tobacco leaf. Amer. Jour. Bot. 20: 565-592.

BENNETT, C. W.

1934. Plant-tissue relations of the sugar-beet curly-top virus. Jour. Agr. Research $48: 665-701$.

EsAU, K.

1933. Pathologic changes in the anatomy of leaves of the sugar beet, Beta vulgaris L., affected by curly top. Phytopathology 23:679-712.

1934a. Cell degeneration in relation to sieve-tube differentiation in curly-top beets. A preliminary note. Phytopathology 24:303-305.

1934b. Ontogeny of phloem in the sugar beet (Beta vulgaris L.). Amer. Jour. Bot. $21: 632-644$.

1935. Ontogeny of the phloem in sugar beets affected by the curly-top disease. Amer. Jour. Bot. 22:149-163.

GoLdsteIn, Bessie.

1926. A cytological study of the leaves and growing points of healthy and mosaic diseased tobacco plants. Bul. Torrey Bot. Club 53:499-599.

Grainger, J., and R. M. HEAFFord.

1933. Some effects of the ordinary tobacco mosaic upon the developmental anatomy of the host plant. Leeds Phil. and Lit. Soc. Proc. 2:406-415.

Holmes, F. O.

1928. Accuracy in quantitative work with tobacco mosaic virus. Bot. Gaz. 86: $66-81$.

1932. Movement of mosaic virus from primary lesions in Nicotiana tabacum L. Boyce Thompson Inst. Contrib. 4:297-322.

Livingston, L. G., and B. M. DugGar.

1934. Experimental procedures in a study of the location and concentration within the host cell of the virus of tobacco mosaic. Biol. Bul. 67:504-512.

SFELIGER, D.

1919. Untersuchungen über das Dickenwachstum der Zuckerrübe (Beta vulgaris L. var. rapa Dum.). Arb. Biol. Reichsanst. Land u. Forstw. 10:149-194.

SEVERIN, H. H. P.

1924. Curly leaf transmission experiments. Phytopathology 14:80-93.

SHEFFIRLD, F. M. L.

1931. The formation of intracellular inclusions in solanaceous hosts infected with aucuba mosaic of tomato. Ann. Appl. Biol. 18:471-493.

VRIES, H. DE.

1879. Beiträge zur speciellen Physiologie landwirtschaftlicher Culturpflanzen. VIII. Wachsthumsgeschichte der Zuckerrübe. Landw. Jahrb. 8:417-498.

Woops, M. W.

1933. Intracellular bodies associated with ring-spot. Boyce Thompson Inst. Contr. $5: 419-434$. 



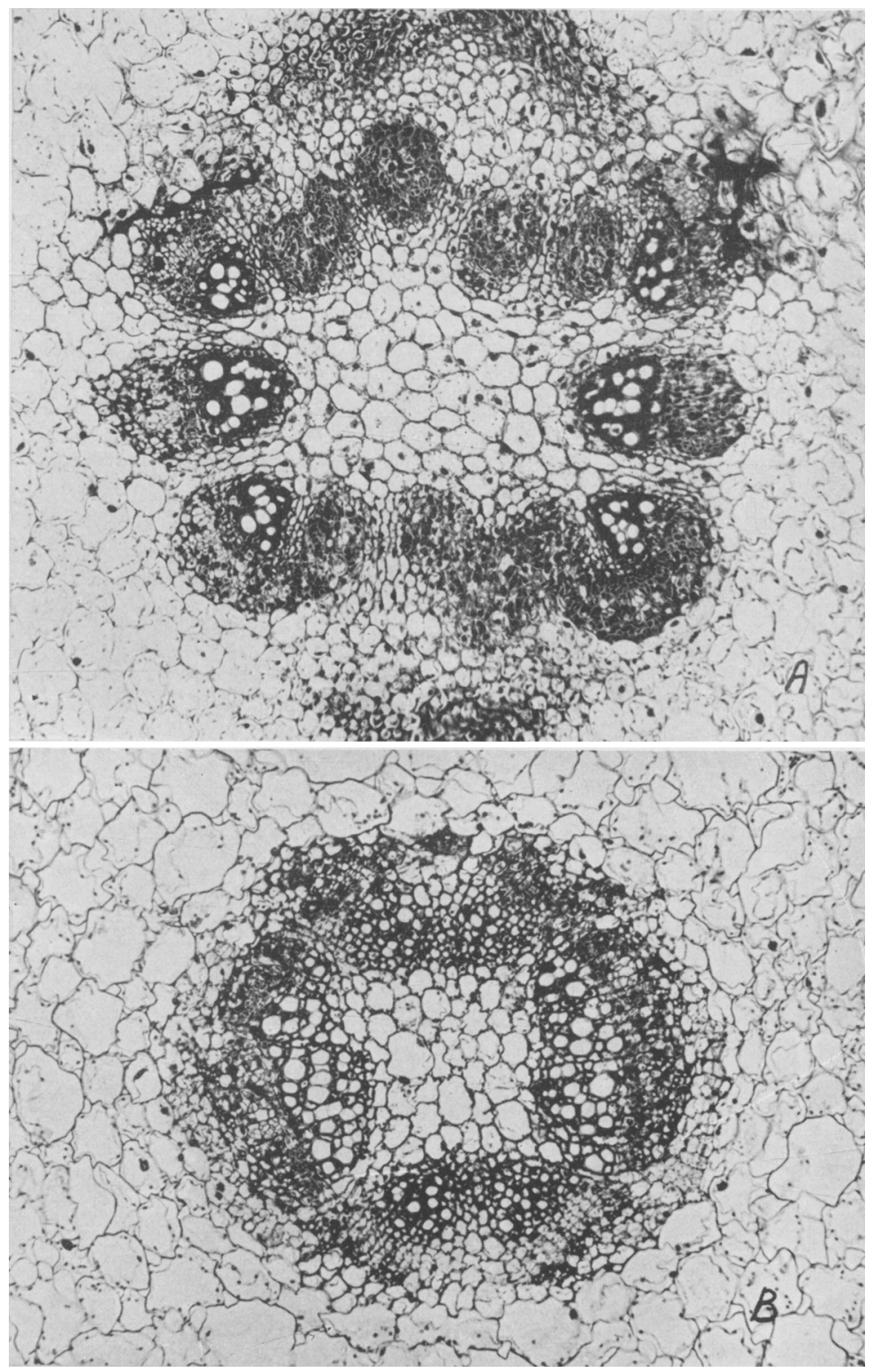

Sections through a diseased young beet plant showing localization of degeneration: $A$, section made above the insertion of cotyledons; secondary necrosis occurs in two bundles right and left above, primary hyperplasia in all the others. $B$, Section made below the insertion of cotyledons; primary hyperplasia is present in all the phloem except in the cotyledonary trace below. (Both $\times 113$.) 


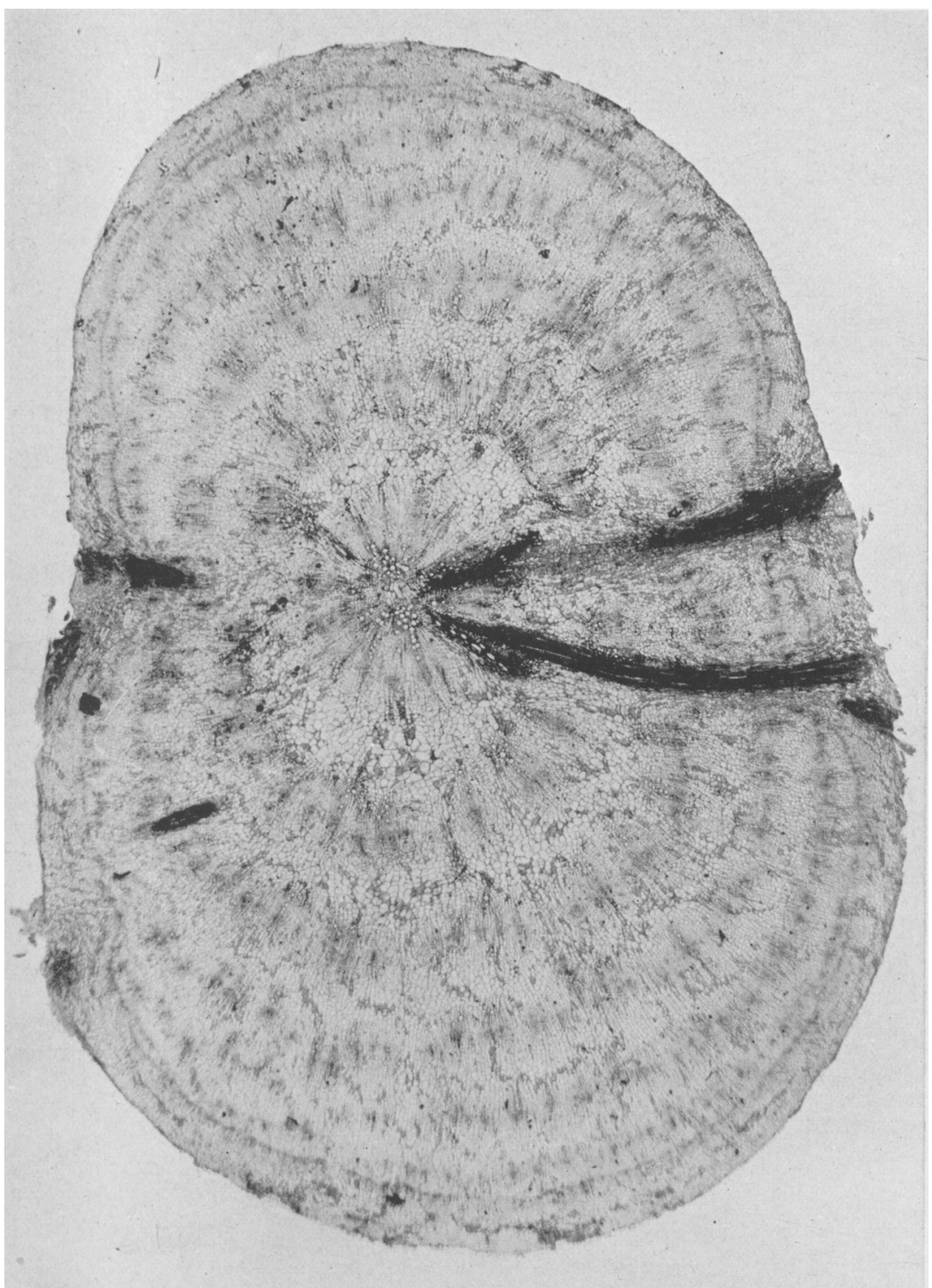

Transverse section of a healthy fleshy taproot $(X 12)$. The darkly stained strands are the traces of lateral roots. 

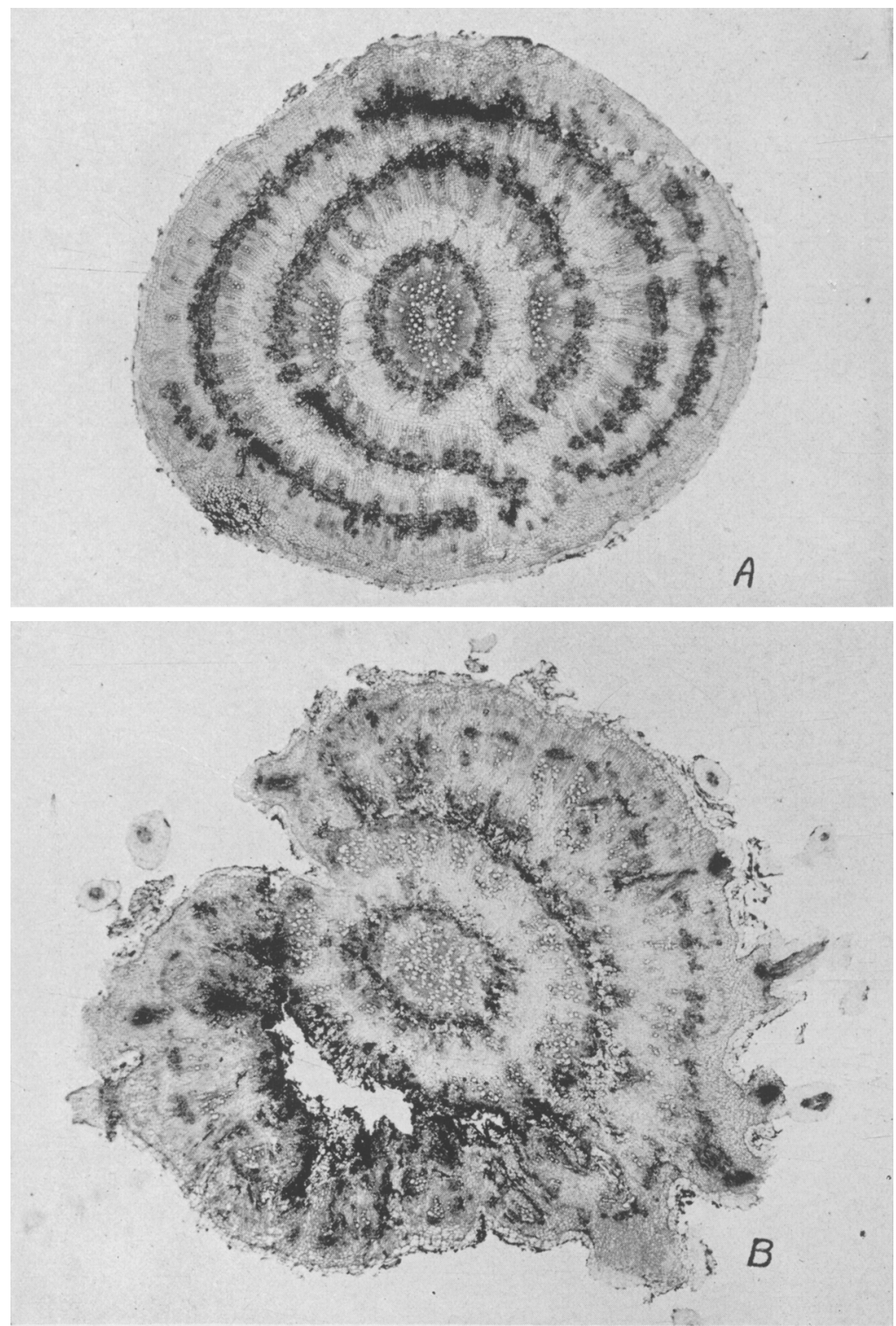

Transverse sections of diseased taproots: $A$, primary hyperplasia and primary necrosis in the phloem; $B$, secondary necrosis and secondary hyperplasia in the phloem. 


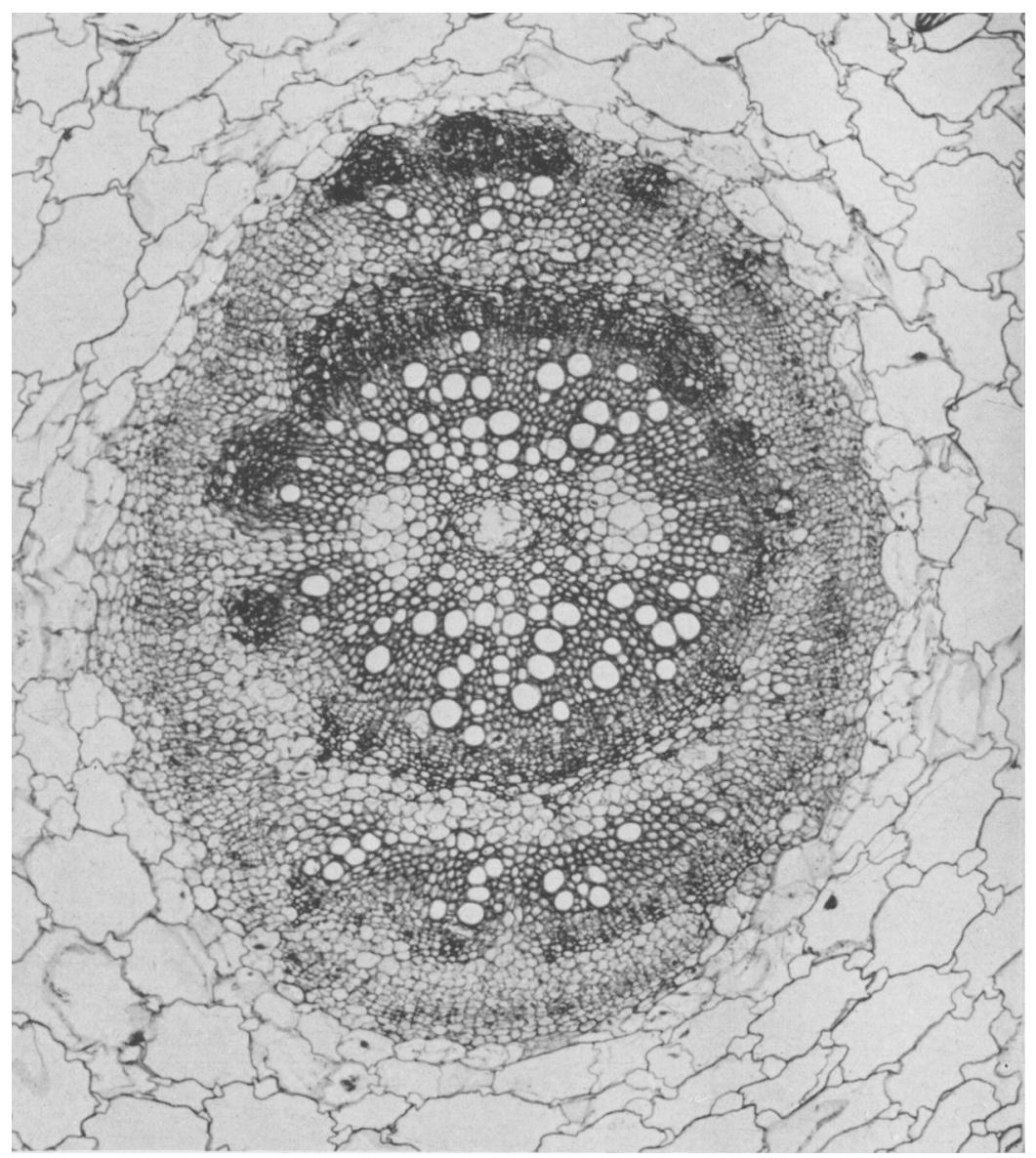

Transverse section of the stele from the hypocotyl of a young diseased beet plant showing localization of phloem hyperplasia (darkly stained) on the inoculated side $(X 81)$. 